NASA Contractor Report 195032

ICASE Report No. 95-5
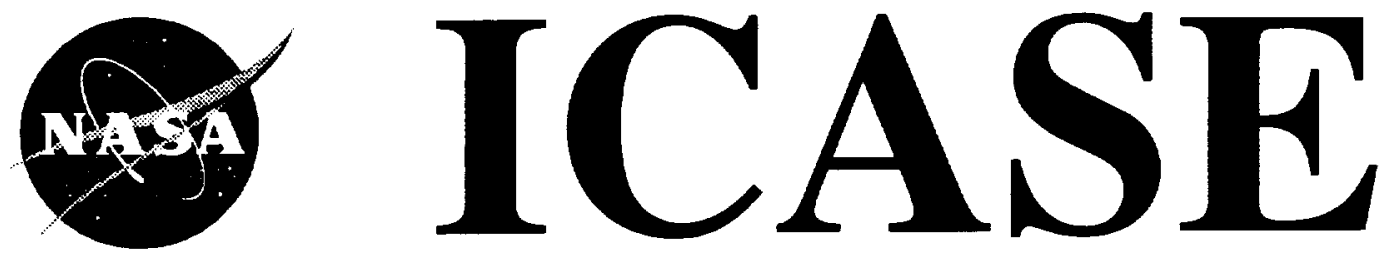

\title{
A STUDY OF THE VORTEX FLOW OVER 76/40-deg DOUBLE-DELTA WING
}

N. G. Verhaagen

L. N. Jenkins

S. B. Kern

A. E. Washburn

(NASA-CR-195032) A STUCY OF THF

VDRTEX FLDW LVER 76/40-DEG

DOURLE-DELTA WING FINAI Report

$N 95-23456$

(ICASE) $34 \mathrm{P}$

Unclas

$63 / 340044412$

Contract NAS1-19480

February 1995

Institute for Computer Applications in Science and Engineering NASA Langley Research Center

Hampton, VA 23681-0001

URA Operated by Universities Space Research Association 



\title{
A STUDY OF THE VORTEX FLOW OVER A 76/40-deg DOUBLE-DELTA WING*
}

\author{
N.G. Verhaagen \\ Delft University of Technology. Delft. the Netherlands \\ L.N. Jenkins \\ NASA Langley Research Center, Hampton, IA \\ S.B. Kern \\ Naval Air Warfare Center, Warminster. PA \\ A.E. Washburn \\ ViGYAN, Inc., Hampton, VA
}

\begin{abstract}
A low-speed wind-tunnel study of the flow about a $76 / 40$-deg double-delta wing is described for angles of attack ranging from -10 to $2.5 \mathrm{deg}$ and Reynolds numbers ranging from 0.5 to 1.5 Million. The study was conducted to provide data for the purpose of understanding the vortical flow behavior and for validating Computational Fluid Dynamics methods. Flow visualization tests have provided insight into the effect of the angle of attack and Reynolds number on the vortex-dominated flow both on and off of the surface of the double-delta wing. Upper surface pressure recordings from pressure orifices and Pressure Sensitive Paint have provided data on the pressures induced by the vortices. Flowfield surveys were carried out at an angle of attack of 10 deg by using a thin 5-hole probe. Numerical solutions of the compressible thin-layer Navier-Stokes equations were conducted and compared to the experimental data.
\end{abstract}

* The present study has been conducted as a cooperative research agreement between NASA Langley Research Center and the Naval Air Warfare Center. The first author was supported by the National Aeronautics and Space Administration under NASA Contract No. NAS1-19480 while in residence at the Institute for Computer Applications in Science and Engineering (ICASE). NASA Langley Research Center, Hampton, VA 23681-0001. 



\section{Introduction}

Strake/wing configurations are employed for several modern peace keeping aircraft and for design concepts of high-speed civil transports. The highly swept strake is an additional lifting surface above which a stable vortex is formed. This strake vortex persists over the wing and induces a strong outflow, which energizes the boundary layer on the upper surface of the wing and keeps it attached to a higher angle of attack than in the case of a wing without a strake. Therefore, strakes increase the lift to drag efficiency of delta wings [1]. At the strake/wing leading-edge kink or juncture, a wing vortex originates that increases in size and strength with distance downstream from the kink. The strake and wing vortices have the same direction of rotation and at high angles of attack their trajectories entwine due to interaction. A limit to these effects is reached once the angle of attack attains values where vortex breakdown occurs over the wing.

Published experimental data on the structure of the subsonic flow over strake/wing configurations is available from several studies carried out in water and wind tunnels on models that are mostly double-delta wings. The results of these studies are used to validate numerical solutions. A summary of the experimental results and available numerical solutions is given by Rom in Ref. 2, and Verhaagen and Maseland in Ref. 3. The experiments indicate that the interaction process and breakdown of the strake and wing vortices depend on the angle of attack, the shape of the leading-edge cross section and the leading-edge kink angle. The latter angle is the difference between the leading-edge sweep of the strake and the leading-edge sweep of the wing. In general, the cross-overpoint of the interacting strake and wing vortices moves downstream with decreasing angle of attack and increasing leading-edge kink angle and Reynolds number. At incidences and kink angles less than 10 deg, no interaction of the vortices occurs. The majority of the experimental and numerical studies were carried out on double-delta wings with strake leading-edge sweep angles between 76 and $80 \mathrm{deg}$ and wing sweep angles near $60 \mathrm{deg}$. These sweep-angle combinations are required for high-speed aircraft configurations to achieve sufficient supersonic-cruise performance.

For highly-maneuverable aircraft, strake/wing configurations are employed which feature smaller wing leadingedge sweep angles to increase wing area and low speed performance. A $76 / 40$-deg planform is representative of such a type of aircraft [4]. Experimental data for double-delta wings that have a $40 \mathrm{deg}$ swept wing are rather limited. Experimental studies by Graves, et al [1]. Brennenstuhl [5], Hebbar, et al [6]. Thompson [7] and Verhaagen [8] provide qualitative insight into the effect of the angle of attack on the crossflow structure, the interaction and breakdown of the strake and wing vortices, and the forces and moments. However, no surface pressures or flowfield data are presented in these references. As far as numerical solutions are concerned, solutions of the Navier-Stokes equations for the flow about a double-delta wing with a 40 deg swept wing were computed by Kern [4]. Hsu and Liu [9], and Ekaterinaris, et al[10]. The solutions predict the interaction and breakdown of the strake and wing vortices as well as the surface pressure levels reasonably well. For a more detailed validation of numerical solutions. additional experimental data are needed on the effect of angle of attack, sideslip and Reynolds number on the vortex flowfield and induced wing surface pressures.

The objective of the present study was to extend the database for $76 / 40$-deg double-delta wings and to compare the experimental data with numerical solutions. This report summarizes the results of the flow visualization tests and surface pressure measurements conducted at angles of attack ranging from - 10 to $25 \mathrm{deg}$, and flowfield surveys conducted at an angle of attack of $10 \mathrm{deg}$. The experimental data for the latter angle of attack is compared with a recent numerical solution computed at the Naval Air Warfare Center (NAWC). Results of the present study have been published earlier in Ref. 11.

\section{Experimental Setup}

\section{Wind Tunnel and Test Conditions}

The tests were carried out in the Basic Aerodynamics Research Tunnel (BART) of the NASA Langley Research Center (LARC). This is a subsonic, open-return wind tunnel with a test section $0.71 \mathrm{~m}$ high, $1.02 \mathrm{~m}$ wide and $3.05 \mathrm{~m}$ long (Fig. 1). The test section consists of two $1.5-\mathrm{m}$ cells, with large windows which facilitate the use of non-intrusive diagnostic and detection techniques. The airflow entering the test section is conditioned by a honeycomb, four anti-turbulence screens and an 11:1 contraction ratio. The variation in longitudinal turbulence 
intensity ranges from approximately $0.03 \%$ at an air speed of $15 \mathrm{~m} / \mathrm{sec}$ to $0.09 \%$ at an air speed of $48 \mathrm{~m} / \mathrm{sec}$. Further details of the wind tunnel facility can be found in Ref. 12 by Sellers and Kjelgaard.

\section{Model}

The model was a stainless steel 76/40-deg swept double-delta wing designed and provided by NAWC (Fig. 2). The model had a chord length of $0.406 \mathrm{~m}$, a span of $0.415 \mathrm{~m}$ and thickness of $9.53 \mathrm{~mm}$. The leading-edge kink was situated at $52 \%$ chord and the wing tip was cropped from the $84 \%$ chordwise station. The sharp leading and trailing edges of the model were broken and rounded to a diameter of $0.13 \mathrm{~mm}(0.005 \mathrm{in}$.). The under surface was beveled at 20 deg over a width of $26.16 \mathrm{~mm}$. The kink section was capable of allowing fillets of different leading edge geometry to be installed [4]. In the present study, only the baseline configuration with straight strake and wing leading edges was investigated. The left upper surface of the model was equipped with 48 pressure orifices of $0.25 \mathrm{~mm}(0.010 \mathrm{in}$.) diameter. Ten orifices were drilled in a spanwise row at $25 \%$ chord, while 19 orifices were drilled both at $75 \%$ and $90 \%$ chord. The pressure tubes exited the model at its lower surface. The model was supported in the tunnel by an internal-balance sting attached to its lower surface (Fig. 3). A fairing was fitted to the lower surface of the model to cover the balance block and the pressure tubes. The angle of attack of the model was controlled remotely and set with an accelerometer mounted on the sting at a short distance behind the trailing edge of the model. The maximum uncertainty in the angle of attack reading was $0.03 \mathrm{deg}$. At large angles of attack, the interaction between the flow over the model and the tunnel walls resulted in a lift interference effect that increased the angle of attack. The pressure field upstream of the sting model support induced an additional upflow. Based on data published in Ref. 13, it is estimated that these interference effects caused the effective angle of attack to be on the order of 2 deg larger than the geometric angle of attack.

\section{Vortex Flow Visualization}

A smoke/laserlight-sheet technique was used to visualize the structure of the vortex flow and to study probe/vortex interference effects. A single column of vaporized propylene glycol was introduced upstream of the tunnel inlet and positioned such that it could be entrained into the vortices generated by the model. A 6-Watt Argon ion laser and a twin-mirrored galvanometer laserlight-sheet generator were used to illuminate the propylene glycol particles and thus the vortices. The vortices were viewed and recorded by two video cameras through a window on the top of the test section. The cameras were set at different viewing angles to capture the flow in planes both normal and parallel to the surface of the model. The laserlight-sheet technique was used at angles of attack ranging from 5 to $22.5 \mathrm{deg}$ and a Reynolds number (Re) of mostly 0.5 million (M).

During the flow visualization tests, the upper surface of the model was covered with black vinyl contact paper to prevent the propylene glycol from settling in the pressure orifices and to enhance the contrast. The covering was also used to overlay a grid on the upper surface of the model to mark the centerline and the stations from 10 to $90 \%$ chord, at intervals of $10 \%$ chord.

\section{Surface Flow Visualization}

Surface flow visualization was used to determine the location of stagnation, attachment and separation lines in the boundary layer pattern on the upper surface of the model. This pattern was visualized using a mixture of titanium dioxide ( $\mathrm{TiO} 2$ ) and kerosene. The mixture was applied to the model and the air speed in the test section was brought up to the test conditions as fast as possible. The development of the surface flow pattern was recorded on video tape. After the mixture on the model surface had dried completely, the contact paper was removed from the model and photographed. The surface flow pattern was investigated at angles of attack ranging from -10 to $22.5 \mathrm{deg}$ and $R e=0.5,1.0$ and $1.5 \mathrm{M}$.

\section{Surface Pressure Measurements}

The distribution of the upper-surface static-pressure coefficient $C p$ at the 25,75 and $90 \%$ chordwise stations was measured at angles of attack ranging from -5.0 to $25.0 \mathrm{deg}$ and $R e=1.0 \mathrm{M}$. To study the effect of the Reynolds number on $C p$, at 10 and $22.5 \mathrm{deg}$ angle of attack $(A O A)$ pressures were acquired at $R e$ ranging from 0.5 to $1.5 \mathrm{M}$. While preparing the model for the surface pressure measurements, 2 of the 10 pressure ports at $25 \%$ chord were found to be unreliable. Therefore, these ports were not used during the testings. The remaining 46 pressure ports in the model were connected to transducers with a maximum range of $+/-1.0$ p.s.i. and an uncertainty of $0.2 \%$. 
The uncertainty in $C p$ is a function of the surface pressure and the dynamic pressure. For $R e=0.5,1.0$ and $1.5 \mathrm{M}$. the maximum absolute uncertainty in the measured $C p$ is estimated to be $+/-0.275,0.079$ and 0.031 . respectively. The dat a remain uncorrected for tunnel wall and support interference effects.

The $C p$ distribution on the entire upper surface of the model was visualized by applying Pressure Sensitive Paint (PSP) at $A O A=10$ and $22.5 \mathrm{deg}$ and $R e=1.0$ and $1.5 \mathrm{M}$. The technique uses a surface coating containing probe molecules that luminesce when excited by an appropriate light source. Oxygen molecules interfere with this process and decrease the amount of luminescence. As a result, the luminescence of the paint varies as a function of the partial pressure of the oxygen. Therefore, the intensity of the luminescence can be related to the static pressure of the air at the coated surface. The paint was excited with eleven tungsten-halogen lamps outfitted with blue stacked filters. The photoluminescence of the paint was detected with a scientific grade digital camera with an amber filter. As part of the calibration of the paint, the ratio of images taken at two pressure conditions was obtained. This corresponds to a "wind-on" condition where the pressures were unknown, and a "wind-off" condition where the model pressure distribution was constant and equal to atmospheric pressure. The offset resulting from the charge-coupled device (CCD) detector dark current and the noise levels of the camera was subtracted from the two images before the ratio was taken. The final paint calibration coefficients were then determined using a linear curve fit with three pressure ports on the model. Further details on the technique can be found in Refs. 14 and 15.

\section{Flowfield Surveys}

Quantitative data of the vortical flowfield over the wing was obtained by surveying the flow using a hemispherical. five-hole probe $(5 \mathrm{HP})$ having a diameter of $3.2 \mathrm{~mm}$. The probe head had a pressure port on the centerline. while four ports. at angle approximately $40 \mathrm{deg}$ off the probe centerline, were located symmetrically around the central pressure port. An iterative calibration procedure using modified equations for the flow around a sphere was used. This procedure is described in Ref. 16 by Kjelgaard. The probe data were reduced to the three velocity components and the static- and total-pressure coefficients. Using this calibration, the $5 \mathrm{HP}$ could be used to measure total flow angles with respect to the probe axis of up to $50 \mathrm{deg}$ and flow velocities of up to $54 \mathrm{~m} / \mathrm{sec}(180 \mathrm{ft} / \mathrm{sec})$. The estimated measurement uncertainty for the total flow angle was 1 deg for flow angles less than 40 deg, and 2 deg for flow angles ranging from 40 to $50 \mathrm{deg}$. The surveys were carried out at $A O A=10 \mathrm{deg}$ in planes normal to the model upper surface at the $50,62.5$ and $75 \%$ chordwise stations. In order to keep the measured velocities within the calibration of the $5 \mathrm{HP}$. flowfield data were acquired at a freestream velocity $U_{\infty}$ of $18 \mathrm{~m} / \mathrm{sec}(R \epsilon=0.5$ M). Earlier experiments indicated that the velocities in the vortex core can reach values of up to three times $U_{\infty}$ [3]. The 5HP was mounted on a five degree-of-freedom traverse ( $x y z$-translation, pitch and yaw) with four degrees under computer control. The traverse enabled movement of the probe with a translation resolution of $10 \mu \mathrm{m}$ in the $x . y$ and $z$ directions, and a yaw resolution of $0.01 \mathrm{deg}$. For all of the survey planes, the probe was yawed to approximately align it with the vortex axis, thus reducing the effective total probe flow angle.

\section{Experimental Test Results}

\section{Vortex Flow Visualization}

Fig. 4 shows pictures of the strake and wing vortices illuminated by a laserlight sheet at $A O A=10 \mathrm{deg}$. The pictures are photoprints of frames from the recorded video tape taken by the video camera that viewed the model from the front at an oblique angle. In the upper picture. the vortex crossflow at $75 \%$ chord was illuminated by the laserlight sheet orientated normal to the model. In the bottom picture, the laserlight sheet was orientated such that it passed through the vortex axes. The dark void along the axes of the vortices indicates a lack of light-scattering smoke particles in this region. The void could possibly be due to the high circumferential velocities near the edge of the subcore through which the smoke particles are centrifuged out of the core. In addition. the high axial velocities in the subcore tend to reduce the density of the smoke. From the picture it is evident that the strake and wing vortices hardly interact at $A O A=10 \mathrm{deg}$. Fig. 5 gives a planview of the vortex axes trajectories as well as the core bursting locations observed at the various angles of attack. The trajectories shown, suggest that the interaction between the strake and wing vortices increases with the angle of attack. This is due to the vortices increasing in size and strength. It can further be noted that the vortices burst before they cross over. At $A O A$ $=15$ and $20 \mathrm{deg}$, the strake vortex burst when it is passing underneath the burst wing vortex. This may indicate 
that the breakdown of the strake vortex is triggered by the burst of the wing vortex. The wing vortex cores hence have been observed to burst earlier than the strake vortex cores. This tendency has also been found in other wind and water tunnel experiments conducted with 76/40-deg swept and 80/40-deg swept double-delta wings [5,7 and 8]. An exception is the water tunnel study of Hebbar [6], who observed the wing vortices to burst downstream of the breakdown point of the strake vortices. In Fig. 6, the range of observed breakdown locations is given for each of the angles of attack investigated in the present test. The breakdown point coordinate is denoted $x b r$ and has been non-dimensionalized by the root chord length $c$. The breakdown location fluctuated over a distance of about $5 \%$ root chord and moved upstream with increasing angle of attack. The location where the core started to expand was taken as the bursting point. Downstream of this location the core was observed to diffuse rapidly. Payne, et al,[17] distinguish a spiral- or bubble-type of vortex core breakdown. Unfortunately, the temporal resolution of the video recordings was not detailed enough to identify the type of breakdown occuring in the strake and wing vortex cores. The effect of Reynolds number on the burst location of the strake vortex was investigated at $A O A=20 \mathrm{deg}$. The burst location was observed to be unaffected by a change in Re from 0.25 to $2.0 \mathrm{M}$. This confirms suggestions made by Erickson [18] that the onset of bursting is independent of $R e$.

Fig. 7 shows a close-up of the strake vortex near the leading-edge kink at $A O A=20 \mathrm{deg}$. In the free shear layer small stationary vortices can be seen which emanate from the leading edge. The vortices are co-rotating and have the same direction of rotation as the primary vortex. This type of vortical flow structure in a free shear layer was for the first time noted by Squire[19]. His illustration has been reproduced here in Fig. 8. Detailed investigations of the vortical structure by Washburn and Visser[13] indicated that these vortices follow streamlines in the flow as they follow a helical path around the primary vortex core.

\section{Surface Flow Visualization}

Fig. 9 shows pictures of the boundary layer flow pattern at $A O A=-10,0,10$ and $22.5 \mathrm{deg}$, as well as sketches indicating the characteristic features of the surface flow pattern at these angles. The boundary layer flow at negative and zero angle of attack was investigated at $R e=1.5 \mathrm{M}$ only. At lower $R e$, the surface shear flow became too weak to generate a clear surface pattern. For positive angles of attack, the patterns were investigated at $R e=0.5$. 1.0 and $1.5 \mathrm{M}$. Only the patterns for $R e=1.0 \mathrm{M}$ are shown here. The effect of $R e$ on the flow pattern will be discussed at the end of this section.

At negative angles of attack, a stagnation line is discernable on the strake upper surface just inboard of the leading edges. Outboard of this line, the boundary layer is directed towards the leading edge where it separates and mixes with the boundary layer from the lower surface. Inboard of the stagnation line, the boundary layer remains attached and flows in the chordwise direction. It can be expected that there will also be an attachment line inboard of the wing leading edges. The resolution of the flow pattern in this region, however, was not detailed enough to discern such a line. Near the cropped leading edge, the surface flow bends towards the tip. This flow mixes with the boundary layer flowing off the lower surface to form a free shear layer that rolls up into a tip vortex.

At zero deg angle of attack, the boundary layer flow pattern shows outflow markings induced by weak strake and wing vortices. Although the upper surface is parallel to the freestream at this angle, support interference effects induce a small upflow angle that causes the flow to separate at the strake and wing leading edges.

At positive angles of attack, the boundary layer flow pattern on the strake changes little with the angle of attack. The pattern is characterized by outflow markings induced by the strake vortices and clear secondary separation lines. The attachment lines of the primary vortex flow are outboard of the symmetry plane at low angles of attack and reaches the wing centerline at $A O A \approx 15 \mathrm{deg}$. The secondary separation lines are straight, giving evidence of an approximately conical strake vortex flow. The boundary layer underneath the strake vortex separates at a spanwise position $y / s \approx 0.70$, indicating that the boundary layer is laminar ( $\mathrm{s}$ denotes local wing semispan ). In the case of a turbulent boundary layer, separation would occur more outboard at $y / s \approx 0.85$ [20]. The topology of the crossflow over the strake is shown in the left sketch of Fig. 10. The free shear layer of the secondary vortex attaches just inboard of the leading edge and induces an inward directed flow on the surface (see insert sketch $A O A=10 \mathrm{deg}$, Fig.9). This flow separates again at the tertiary separation line. Between the latter line and the secondary separation line a region of accumulated surface oil was visible in the experiment. At low Re, the surface shear in this region was too weak to generate a clear pattern. At high angles of attack and $R \epsilon$, the pattern showed markings of an outflow that is assumed to be induced by the tertiary vortex. The tertiary separation line was visible from near the apex to the leading edge kink. Downstream of the leading edge kink, this line disappears as the tertiary vortex is supposed to be entrained into the stronger wing vortex. 
Downstream of the leading edge kink, the effects of the angle of attack on the surface pattern are much st ronger. Up to $A O A=10 \mathrm{deg}$, the shear flow pattern induced by the strake and wing vortices and accompanying secondary separation lines remain individually distinguishable up to the trailing edge. The conjectured topology of the crassflow at $A O A=10 \mathrm{deg}$ is shown in the right sketch of Fig. 10. It is characterized by a double-branched wing vortex core fed by vorticity from free shear layers that are connected to the wing leading edge and the strake vortex core.

Beyond $A O A=10 \mathrm{deg}$, the strake vortex secondary separation lines vanish starting at the trailing edge. indicating that the secondary separation is suppressed. Both the strake and wing vortex cores break down over the wing. Just upstream of the bursting point of the strake vortex, the surface pattern gives evidence of the strong outward bending of this vortex. Downst ream of the bursting point a wide region of turbulent surface flow is visible. Outboard of the wing vortex secondary separation line elongated regions of accumulated and circulating surface fluid were observed. These regions tend to move towards the kink with increasing angle of attack. Near the wing tip a rather complex surface flow pattern is visible. This pattern is assumed to be generated by the bluff-body type wake flow downstream of the burst strake vortex and by the wing tip vortex. Near the tip a focus was observed in the surface flow pattern. This focus induced an upstream flow locally at the trailing edge.

The effect of the Reynolds number on the surface pattern is illustrated in Fig. 11 for $A O A=10$ and 22.5 deg. On the strake, the pattern changes little when $R e$ increases from 0.5 to $1.5 \mathrm{M}$. There were no signs of boundary layer transition from laminar to turbulent. On the wing. the strake vortex secondary separation lines are clearly visible at $A O A=10 \mathrm{deg}$ when $R e=0.5$ and $1.0 \mathrm{M}$. From about the $6.5 \%$ chordwise position. the secondary separation lines at $R e=1.0 \mathrm{M}$ are located outboard the lines at $R e=0.5 \mathrm{M}$. This is a consequence of the transition of the boundary layer underneath the strake vortex from laminar to turbulent. The secondary separation lines have vanished at $R e=1.5 \mathrm{M}$, indicating that no secondary vortices are induced by the strake vortices at this $R e$. Another possibility may be that the secondary vortices have moved outboard and merged with the wing secondary vortices. At $A O \dot{A}=22.5 \mathrm{deg}$, on the wing no strake vortex secondary separation lines were visible at the Re investigated. Reynolds number effects were further noted on the spanwise location of the wing vortex secondary separation lines. These lines tend to bend outboard with increasing Re due to transition of the boundary layer underneath the wing vortex from laminar to turbulent.

\section{Surface Pressure Measurements}

Fig. 12 shows the effect of the angle of attack on the upper surface $C p$ at $25 \%$ chord for $R e=1.0 \mathrm{M}$. The $C p$ distribution has been plotted versus the wing lateral coordinate $y$, non-dimensionalized by the local wing semispan s. At $A O A=0 \mathrm{deg}$, a small suction peak is induced by the weak strake vortex near the leading edge. Inboard of the suction peak. flow incident to the wing causes a region of positive $C p$. The angle of attack has little effect on the crossflow structure sketched in Fig. 10. The size and circulation of the strake vortex, however, increases with the angle of attack, resulting in a growing suction peak. Outboard of this peak the pressure curves rise slightly due to the influence of the secondary and tertiary vortices. The level of suction induced by these vortices is about the same as that induced by the primary vortex, confirming that the boundary layer underneath this vortex is laminar. In the case of a turbulent boundary layer. the suction induced by the primary vortex would be larger, while the opposite would be the case for the suction induced by the secondary vortex. There would probably be no tertiary vortex [21].

The effect of the angle of attack on the Cp-distribution at $75 \%$ chord, shown in Fig. 13. can be explained using Fig. 14, which illustrates the effect of the angle of attack on the topology of the crossflow at this station. The latter figure is based on the results of the flow visualization tests.

At $A O A=0 \mathrm{deg}$, a weak strake vortex suction peak and stronger wing vortex suction peak can be detected in the $C p$-distribution. As the angle of attack is increased to $5 \mathrm{deg}$, a slight increase can be noted in the strake vortex suction peak and a strong increase of the suction induced by the wing vortices. Outboard of both the strake and the wing vortex suction peak, a suction peak is induced by the accompanying secondary vortex. Lp to $A O A=5 \mathrm{deg}$, the strake and wing vortices are small and not connected to each other. In the gap between these vortices flow is incident to the wing, thus causing a small region of positive $C p$ at about $y / s \approx 0.6$. This region of positive $C p$ has also been noted in the $C p$ data of an identical double-delta wing investigated at the Delft Iniversity of Technology (TUD) [22]. When the angle of attack is increased, the strake and wing vortex cores hecome interconnected. Ip to $A O A=12.5 \mathrm{deg}$, the suction induced by the strake and wing primary and secondary vortices can be seen to increase. The increase in suction of the wing vortex secondary vortex is only small. This may be due to the 
transition of the boundary layer underneath the wing vortex from laminar to turbulent which reduces the influence of the secondary vortex. Beyond $A O A=10 \mathrm{deg}$, the strake and wing vortices start to coil around each other. As a consequence, the strake vortex moves closer to the wing surface and more outboard, while the wing vortex moves upwards and inboard. The effect of these displacements is noticable in the $C p$-curves; up to $A O A=20$ deg the suction peak of the strake vortex moves outboard and increases in size, while the suction peak of the wing vortex moves inboard and reduces rapidly. At $A O A=20 \mathrm{deg}$, the wing vortex is overhead the strake vortex and only one suction peak is induced on each wing half. At $A O A=25 \mathrm{deg}$, the pressure distribution is affected by the burst of the strake vortex core. As a result, the suction peak not only collapses, but also spreads in the spanwise direction. The latter is caused by the radial expansion of the burst vortex core, through which the circulation previously contained in a narrow core is redistributed over a wider region.

The effect of the angle of attack on the $C p$ measured at $90 \%$ chord is shown in Fig. 15. At this station, suction is less than at $75 \%$ chord for all angles of attack considered. Separate strake and wing vortex suction peaks were measured up to $A O A=12.5 \mathrm{deg}$. At $15 \mathrm{deg}$, these peaks have merged into a single peak, while at higher angles of attack the surface pressures become affected by vortex bursting.

The effect of Reynolds number on $C p$ was investigated at $A O A=10$ and 22.5 deg by acquiring data at $R e$ ranging from 0.5 to $1.5 \mathrm{M}$. At both $A O A$, the effect of $R e$ on the $C p$ distribution at $25 \%$ chord is of the order of the measurement accuracy. At $75 \%$ chord, the upper plot of Fig. 16 shows that at $A O A=10$ deg there is a clear effect in the region dominated by the strake vortex. Due to the transition of the boundary layer underneath the strake vortex from laminar to turbulent, the secondary vortex and its suction have become nil at $R e=1.5 \mathrm{M}$. This is in accordance with the surface flow pattern where the secondary separation lines have vanished at this Re. As a result, the primary vortex is located closer to the wing surface, inducing a higher suction than at $R e=0.5 \mathrm{M}$. On the wing vortex side, transition of the boundary layer results in a smaller and more outboard located secondary vortex. As a consequence, the primary wing vortex is expected to move slightly outboard as well, explaining the slight outboard shift of the wing vortex suction peak that can be noted when $R e$ is increased from 0.5 to $1.5 \mathrm{M}$. The lower plot of Fig. 16 shows that at $A O A=22.5 \mathrm{deg} R e$ has a similar effect on the suction induced by the strake primary and secondary vortices as noted at $A O A=10 \mathrm{deg}$.

\section{Computations}

About the double-delta wing a spherical C-O topology grid was created using a three-dimensional hyperbolic grid generation method in conjunction with an interactive grid generation system. The geometry and grid of the doubledelta wing upper surface is shown in Fig. 17. The surface grid had 113 points in the chordwise direction and 129 points in the circumferential direction with an equal number of points on the upper and lower surfaces. This grid was clustered at the apex, the leading edges and the trailing edge by using hyperbolic tangent distributions. The leading edges were locally rounded to a diameter matching the wind tunnel model. A minimum of 13 points defined the curvature of the leading edges. The wing surface was used as the initial condition for the hyperbolic grid generation method to create the spherical C-O type field grid, shown in Fig. 18. The field grid was generated by marching in the direction normal to the surface. Close to the surface 21-25 points were taken to sufficiently resolve the boundary layer and predict flow separation. The $y+$ value of the first point off of the surface was no larger than 1 for the Reynolds numbers simulated. The outer boundary of the grid was taken 2-2.5 chord lengths away from the surface in all directions and 73 points were used in the normal direction to extend the grid to the far field. To further resolve the convection of vortical flow, a grid of the same family of points, with twice the number of points in each direction, was embedded into the major grid above the wing using the Chimera or Overset methodology (see inset of Fig. 18). The connectivity between the two grids was prescribed by using the Domain Connectivity Function Three-Dimensions (DCF3D) developed at the NASA Ames Research Center. The embedded grid extended from near the apex to the downstream outflow boundary in the chordwise direction, from close to the symmetry plane to the leading edges in the spanwise direction, and from the boundary layers edge (selected as the 21 st point off the surface) to a maximum of 0.6 chord lengths above the wing in the normal direction. The dimensions of the embedded grid were $255 \times 177 \times 73$ and the composite grid totaled slightly over 3.4 million points.

To solve the flow over the double-delta wing, the compressible thin-layer Navier-Stokes code OVERFLOW developed at the NASA Ames Research Center was used. The code has an option to use the diagonal form of the implicit Beam and Warming type approximate factored scheme developed by Pulliam and Chaussee. OVERFLOW 
was run at $A O A=10 \mathrm{deg}$, at a Mach number of 0.2 and $R e=0.5 \mathrm{M}$ with completely laminar flow. Each run took 24 hours on a Cray C90 computer. Since the computational grid planes did not line up with constant chord sections, the CFD solution was interpolated onto the spacial coordinates used in the experimental flowfield surveys. A code was developed, which used a stencil walk, an iterative search algorithm, and tri-linear interpolation to efficiently perform the interpolation.

Pseudo-time stepping using time steps scaled to grid metrics and a CFL number maximum limit was used to accelerate the convergence of the simulation. For each of these cases. the L2 norm of the residuals dropped 2 orders of magnitude by 1000 iterations, at which point the major vortical structures formed. The residuals remained constant for the additional 2000 iterations run, indicating that there were small regions in the flowfield that remained unsteady. By the 1500th iteration, the secondary separation lines, caused by the strake and wing vortices had formed and were refined slightly until the final 3000th iteration. Inspection of the flowfield revealed that the portion of the flowfield outhoard of the wing vortex secondary separation line changed slightly up to the last iteration. These changes were caused by spurious accumulation and dissipation of regions of vorticity embedded within the wing leading edge feeding shear layer. As these regions of vorticity appeared above the wing surface, they perturbed the local boundary layer separation and surface pressure outboard of the wing vortex secondary separation line. The strake vortex and wing vortex secondary separation lines, and local surface pressure inboard of the wing vortex secondary separation line, however, remained relatively constant with iteration. No such perceptable perturbations existed over the strake portion of the wing. Therefore, the solutions are considered converged and valid in all portions of the flowfield except in the region outboard of the wing vortex secondary separation line. Time-accurate unsteady simulations would be required to capture the time evolution of these vortical structures and their impact on the local flowfield as performed over a single delta wing by Gordnier and Visbal [23].

\section{Comparison between Solution and Experiment}

\section{Flowfield Data}

The vortex flow over the wing was surveyed at $A O A=10 \mathrm{deg}$ and $R e=0.5 \mathrm{M}$ in order to provide data for the validation of the Navier-Stokes solution at these conditions with fully laminar flow. The upper plots of Figs. 19 to 21 show the velocity vectors, the contours of constant chordwise velocity component $u / U_{\infty}$, and the total-pressure coefficient $C p_{t}$ measured at $50,62.5$ and $75 \%$ chord. $C p_{t}$ has been defined here as the difference between the local total pressure and the free stream static pressure, non-dimensionalized by the freestream dynamic pressure. The computed data is presented in the lower plots. The chordwise stations are located well upstream of the bursting point of the strake and wing vortices at this angle of attack. The laserlight-sheet flow visualization indicated that the bursting point can be pushed upstream by the 5HP when the angle between the probe and vortex axes is large. This undesired effect was avoided by carrying out the surveys at $50,62.5$ and $75 \%$ chord with the probe yawed at angles of 7,20 and $15 \mathrm{deg}$, respectively. Since the rotation about the pitch axis was not computer controlled, the probe pitch angle was kept at zero deg during the surveys. At $75 \%$ chord, this unfortunately resulted in a void in the data measured beneath the wing vortex. In this region probe flow angles were encountered that were outside the calibration range of the $5 \mathrm{HP}$. Due to the symmetry of the flowfield, the data is presented for the right half of the double-delta wing only.

The vector plots illustrate the development of the vortex flow which exists downstream of the kink. For clarity, these plots do not show all the measured and computed data points. The development of the strake and wing vortices from 50 to $75 \%$ chord is reasonably well predicted by the solution. On the strake. the primary vortex core is predicted to be slightly outboard of the measured location, while on the wing the strake and wing vortex cores are predicted to be slightly inboard of the measured locations. The reason for this will be discussed in the subsequent section.

The $u / U_{\infty}$ and $C p_{t}$ measured in the strake vortex changes hardly from 50 to $62.5 \%$ chord. From 62.5 to $75 \%$ chord, the magnitude of this data can be seen to decrease slightly. This may be due to the fact that at some downstream distance from the kink the strake vortex is no longer fed with vorticity from the strake leading edge. The wing vortex, on the other hand, increases rapidly in strength with downstream distance from the kink and at $62.5 \%$ chord in this vortex much larger $u / C_{\infty}$ and lower $C p_{t}$ values are recorded than in the strake vortex. These tendencies are well predicted by the solution. The magnitude of the computed quantities is in general lower than 
that measured in the experiment.

\section{Surface Flow}

Particle traces, resembling surface oil flow visualization, for the laminar flow solution at $A O A=10$ deg and $R e=0.5 \mathrm{M}$ are compared with the experiment in Fig. 22. On the strake, the secondary separation line and the flow that is entrained is well predicted. A tertiary separation line is also predicted whose position agrees with the experiment. Flow entrainment towards the tertiary separation line in the outboard direction is weak due to a lack of grid resolution. At the kink, the surface flow resembles the experiment, in that the strake vortex tertiary: separation line vanishes, and the flow is entrained outboard towards the wing vortex secondary separation line. A slight outboard bending of the strake vortex secondary separation line near the kink, caused by the influence of the formation of the wing vortex, is also predicted.

Over the wing, the strake vortex secondary separation line continues to exist. The strake vortex secondary separation line is predicted to be a few percent semispan inboard of the experimental position. Downstream of the $85 \%$ chordwise location, the predicted secondary separation line bends inboard to become parallel to the centerline at the trailing edge. The wing vortex secondary line is also predicted inboard of the experimental position. The outboard bending of the wing vortex secondary separation line noted in the experiment was caused by transition from laminar to turbulent flow. Since the flow simulated was purely laminar, this outboard bending could not be predicted. The position of the simulated wing vortex secondary separation line was therefore inboard of the experimental line, which forced the strake vortex and secondary separation line inboard as well. Another key feature of the surface flow captured is the apparent focus near the cropped portion of the wing. In this location. the solution is converged and flow issues from a point in all directions, but predominently upstream, as observed in the experiment. Upstream and outboard of this focus, the surface flow prediction is unreliable due to local lack of convergence, as discussed in the section on Computations.

\section{Surface Pressure}

Fig. 23 compares the measured and computed $C p$ at 25,75 and $90 \%$ chord for $A O A=10$ deg and $R e=0.5 \mathrm{M}$. The shape of the $C p$ distributions induced by the strake primary and secondary vortices is in general well predicted by the solution. At $25 \%$ chord, the strake vortex suction peak is predicted to be far outboard of the measured location. It should be reminded here, that the effective $A O A$ may be on the order of $12 \mathrm{deg}$ in the experiment. A reduction of $A O A$ from 12 to $10 \mathrm{deg}$, decreases the strake vortex suction and moves its peak outboard, but not so much that it matches the computed peak. At 75 and $90 \%$ chord, both the strake and the wing vortex are predicted to be slightly inboard of the location found in the experiment. A reduction of the experimental $A O A$ from 12 to 10 deg increases the $C p$ induced by the strake and wing vortices by about 0.2 . The differences between the predicted and experimental $C p$ distributions hence become smaller when this is taken into account.

Fig. 25 shows coloured pictures of the computed $C p$ distribution on the entire upper surface of the double-delta wing and the $C p$ distribution that was determined from PSP test results. The PSP results shown were obtained at $R e=1.5 \mathrm{M}$, because the resolution at this $R e$ was better than that at lower $R e$. Since the computations were performed at $R e=0.5 \mathrm{M}$, a direct comparison with the PSP results is not justified. The PSP picture shows white spots on the central part of the strake, suggesting a positive $C p$ in this region. This is incorrect and due to glare from the lamps that were used to excite the PSP. Both pictures clearly show the negative- $C p$ regions induced by the strake and wing vortices. The wing vortex can be seen to induce a lower $C p$ than the strake vortex. In the PSP experiment, a $C p$ as low as -3.1 was induced by the wing vortex just downstream of the kink. This agrees well with data measured on an identical double-delta wing at TUD, where under similar test conditions a minimum $C p$ of -2.9 was recorded at $60 \%$ chord [22]. The computed wing vortex pressure field can be seen to suddenly expand at about the $85 \%$ chordwise position. This correlates well with the vortex core bursting location observed in the laserlight sheet flow visualization tests(Fig. 8).

\section{Turbulent Flow Computations}

Currently, computations are performed with OVERFLOW running at $R e=1.0 \mathrm{M}$ with fully turbulent flow. To simulate completely turbulent flows, the Baldwin-Barth one equation turbulence model is used. The first results indicate that the cores of the strake and wing vortices are predicted to be outboard when compared to the laminar case. This is accompanied with an outboard shift of the secondary separation lines of both vortices. At $25 \%$ chord, the surface $C p$ is stronger negative for the turbulent case, while the $C p$ induced by the secondary vortex is less 
negative. This is in accordance with earlier experimental results [21]. At $75 \%$ chord, the $C p$ induced by the strake vortex is nearly identical for either the laminar or turbulent case (Fig. 24). The wing vortex suction, however, is stronger and more outboard compared to the laminar flow case.

\section{Conclusions and Recommendations}

A low-speed wind-tunnel study of the flow about a 76/40-deg double-delta wing is described that was carried out at angles of attack ranging from - 10 to $25 \mathrm{deg}$ and at Reynolds numbers from 0.5 to $1.5 \mathrm{M}$. Flow visualization tests have provided an insight into the effect of the angle of attack and Reynolds number on the vortex-dominated flow on and off the surface of the double-delta wing. Surface pressure recordings and PSP tests have provided data on the pressures induced by the vortices. Flowfield data were obtained at an angle of attack of 10 deg by surveying the flow over the model using a thin 5-hole probe. The data for this angle of attack has been used to validate the solution of the thin-layer Navier-Stokes equations for fully laminar flow. The solution is shown to well predict the behavior of the flow on and off the upper surface of the double-delta wing.

For a more complete validation of the numerical methods, the experimental tunnel wall and model support interference effects should be quantified. The numerical methods, on the other hand, should be extended in order to be capable to calculate these effects.

For further validation of the numerical solutions for the flow over the present double-delta wing, additional experimental data are required, e.g., surveys of the vortex flowfield at angles of attack other than 10 deg and balance measurements.

\section{$7 \quad$ Acknowledgements}

The first author sincerely thanks Dr. M.Y. Hussaini of ICASE and Dr W.L. Sellers III of NASA LaRC for making it possible for him to participate in the testings at BART. All authors are indebted to Dr. K.D Visser for the valuable discussions and his assistance during the tests, and to $\mathrm{Mr}$ B. Gaddy for preparing the model and test setup. Computations were performed on the NASA Numerical Aerodynamic Simulation (NAS) facility.

\section{References}

[1] Graves, T.V., Nelson, R.C., Schwimley, S.L. and Ely, W.L., "Aerodynamic Performance of Strake Wing Configurations." NASA High-Angle-of-Attack Technology Conference, NASA LaRC, October 1990

[2] Rom, J., "High Angles of Attack Aerodynmamics: Subsonic, Transonic, and Supersonic Flows," SpringerVerlag, New York. 1991

[3] Verhaagen. N.G. and Maseland, J.E.J., "Investigation of the Vortex Flow over a $76 / 60$-deg Double-Delta Wing at $20 \mathrm{deg}$ Incidence," AIAA-91-3208-CP, Baltimore, September 1991

[4] Kern, S.B., "Numerical Investigation of Vortex Flow Control through Small Geometry Modifications at the Strake/Wing Junction of a Cropped Double-Delta Wing," AIAA-92-0411. Reno, January 1992

[5] Brennenstuhl, U., "Experimentelle und Theoretische Untersuchungen ueber die Wirbelbildung an Doppel-deltafluegeln." PhD Dissertation. Technical University Carola-Wilhelmina, Braunschweig, 1985

[6] Hebbar. S.K., "A Visualization Study of the Vortical Flow over a Double-Delta Wing in Dynamic Motion," AIAA-933425-CP. Monterey, August 1993

[7] Thompson. D.H., "A Visualisation Study of the Vortex Flow around Double-Delta Wings". ARL-AERO-R-165, Melbourne, August, 1985

[8] Verhaagen. N.G., "An Experimental Investigation of the Vortex Flow over Delta and Double-Delta Wings at Low Speed." TUD Report LR-372, Delft. September 1983

[9] Hsu, C.-H. and Liu, C.H.. "Lpwind Navier-Stokes Solutions for Leading-Edge Vortex Flows." AIAA-89-0265, Reno, January 1989 
[10] Ekaterinaris, J.A., Coutley, R.L., Schiff, L.B. and Platzer, M.F., "Numerical Investigation of the Flow over a Double Delta Wing at High Incidence," AIAA-91-0753, Reno, January 1991

[11] Verhaagen, N.G., Jenkins, L.N., Kern, S.B., and Washburn, A.E.. "A Study of the Vortex Flow over a $76 / 40-$ deg Double-Delta Wing," AIAA-95-0650. Reno, January 1995

[12] Sellers III, W.L., and Kjelgaard, S.O., "The Basic Aerodynamics Research Tunnel," AIAA-88-1997, San Diego, May 1988

[13] Washburn, A.E. and Visser, K.D., "Evolution of Vortical Structures in the Shear layer of Delta Wings," AIAA-94-2317, Colorado Springs, June 1994

[14] Morris, M. J.. "Surface Pressure Measurements Based on Photoluminescence," U. S. Congress on Theoretical and Applied Mechanics, June 27-30, 1994

[15] Morris, M. J., Donovan, J. F., Kegelman, J. T., Schwab, Levey, R. L., and Crites, R. C.: "Aerodynamic Applications of Pressure-Sensitive Paint," AIAA J., Vol. 31, No. 3, March 1993, pp 419-425

[16] Kjelgaard. S.O., "Theoretical Derivation and Calibration Technique of a Hemispherical-Tipped, Five-Hole Probe," NASA TM 4047, December 1988

[17] Payne, F.M., Ng, T.T. and Nelson, R.C., "Visualization of Leading Edge Vortices on a Series of Flat Plate Delta Wings," NASA CR-4320, April 1991

[18] Erickson, G. E., "Vortex Flow Correlation," Technical Report AFWAL-TR-80-3143 Flight Dynamics Laboratory, Wright Patterson Air Force Base, January 1981.

[19] Squire, L.C.. "An Experimental Investigation of the Characteristics of Some Plane and Cambered 65-deg Delta Wings at Mach Number from 0.7 to 2.0," ARC Reports and Memoranda No.3305, July 1961

[20] Visser, K.D. and Washburn, A.E., "Transition Behavior on Flat Plate Delta Wings," AIAA-94-1850, Colorado Springs, June 1994

[21] Hummel, D., "Zur Umstroemung scharfkantiger schlanker Deltafluegel bei grossen Anstellwinkeln," ZFW 15, 1967, Vol. 10, pp $376-38.5$

[22] Rogers, D.J., private communication

[23] Gordnier, R.E. and Visbal, M.R., "Unsteady Vortex Structure over a Delta Wing," Journal of Aircraft, Vol 31, No. 1, Jan-Feb 1994. 


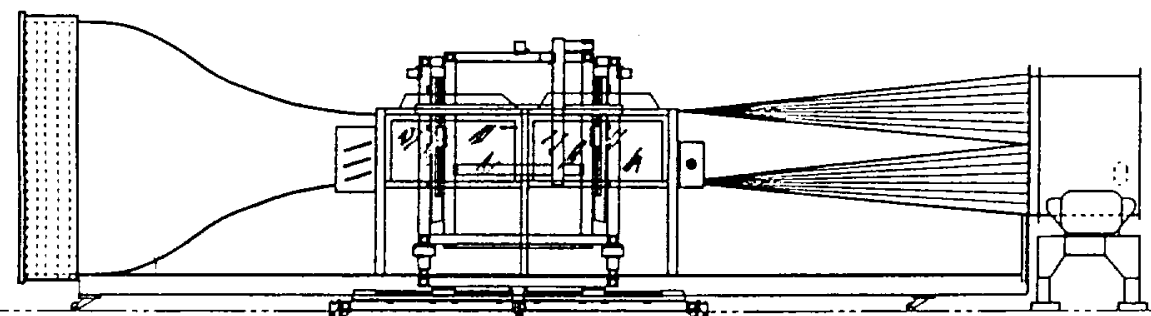

Figure 1: BART wind tunnel

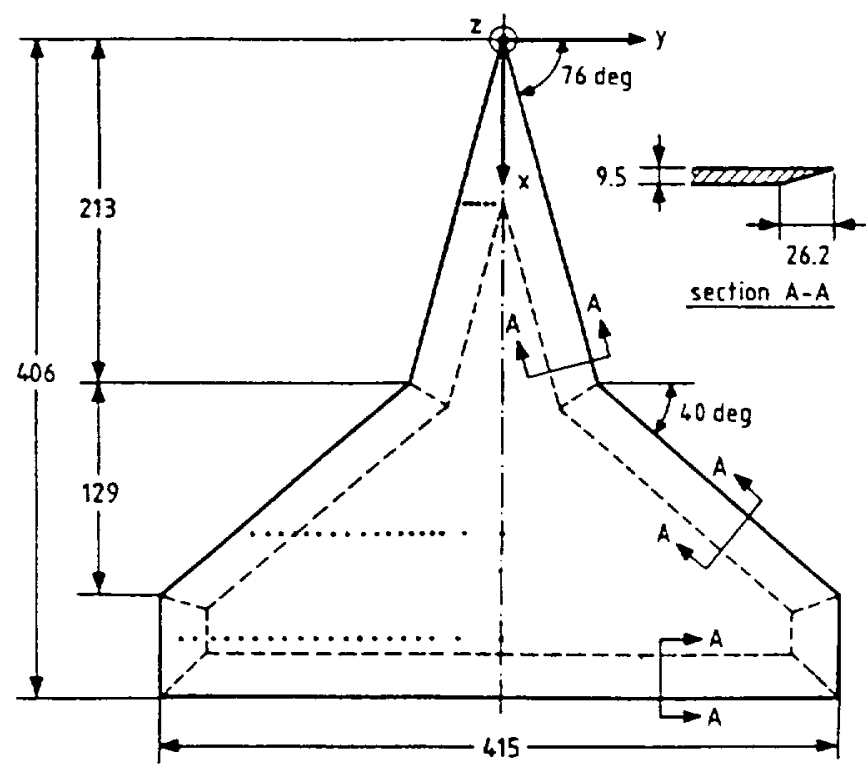

Figure 2: Model geomelry (dimensions in mm)

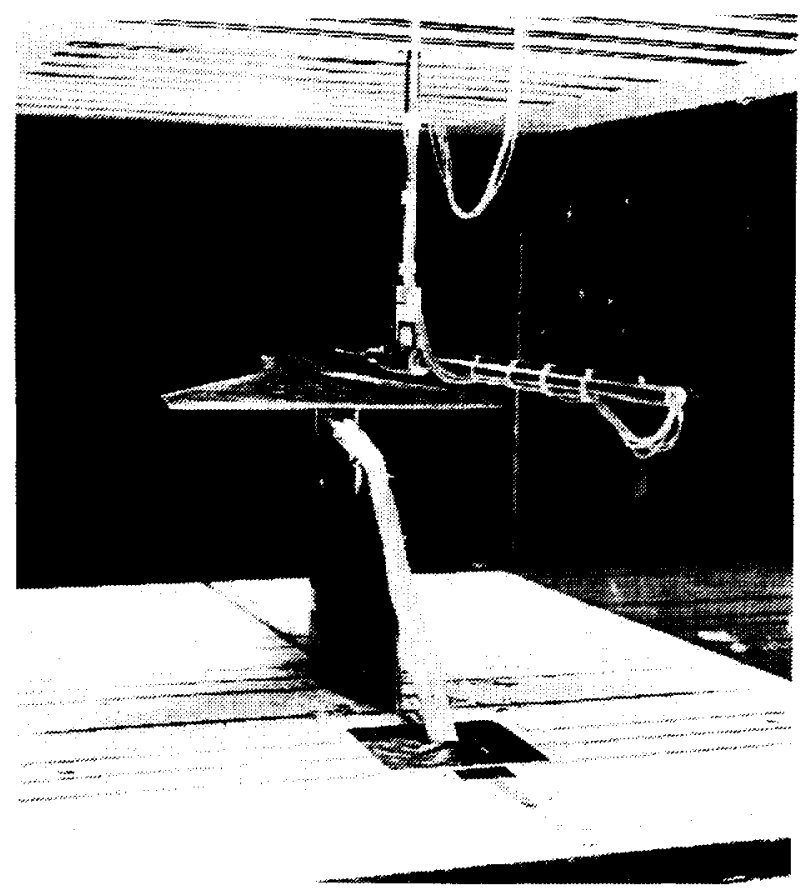

Figure 3: Model in wind tummel 

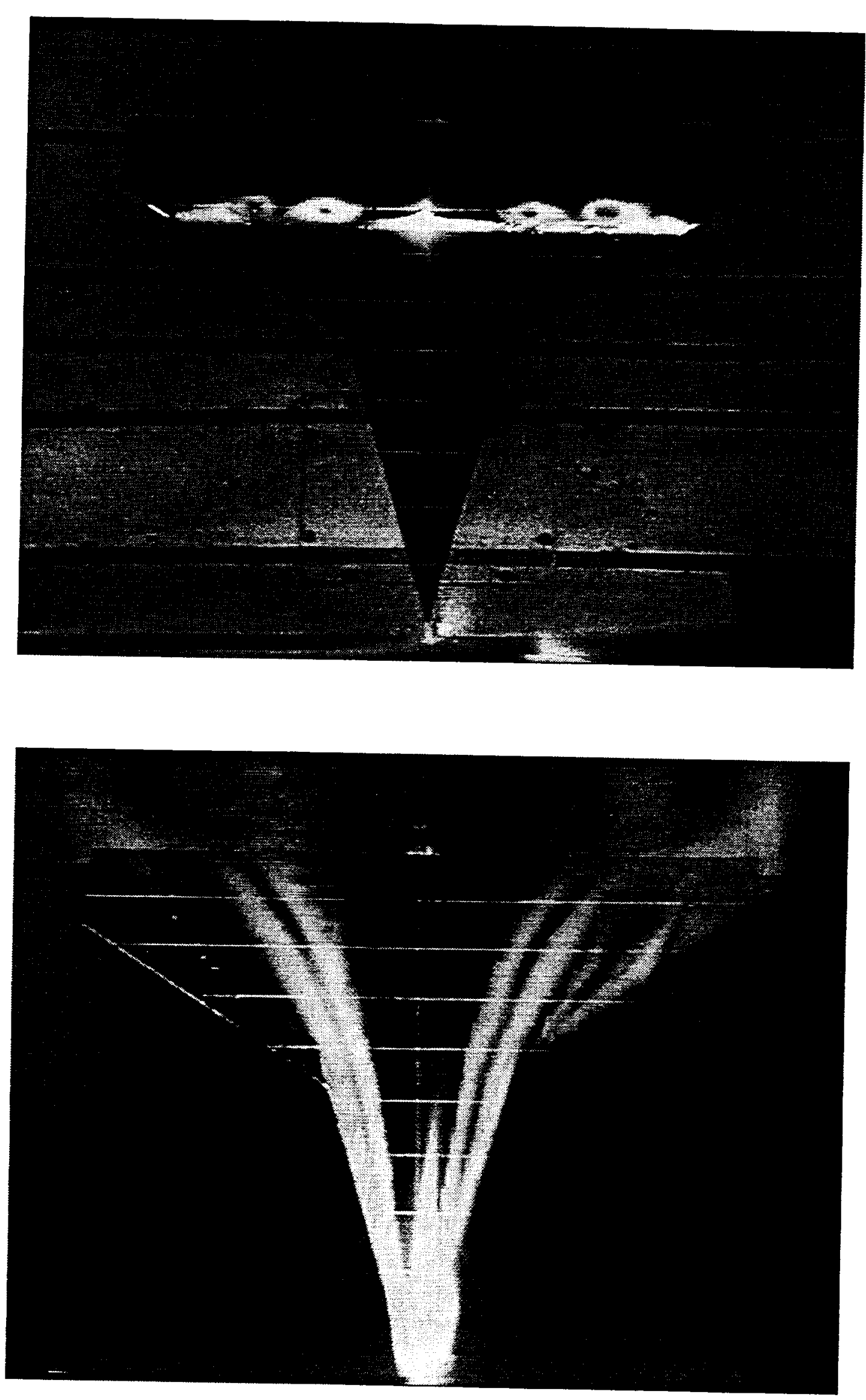

Figure 4: Vortex flow illuminated by laserlight sheet; $A O A=10 \mathrm{deg}$ 


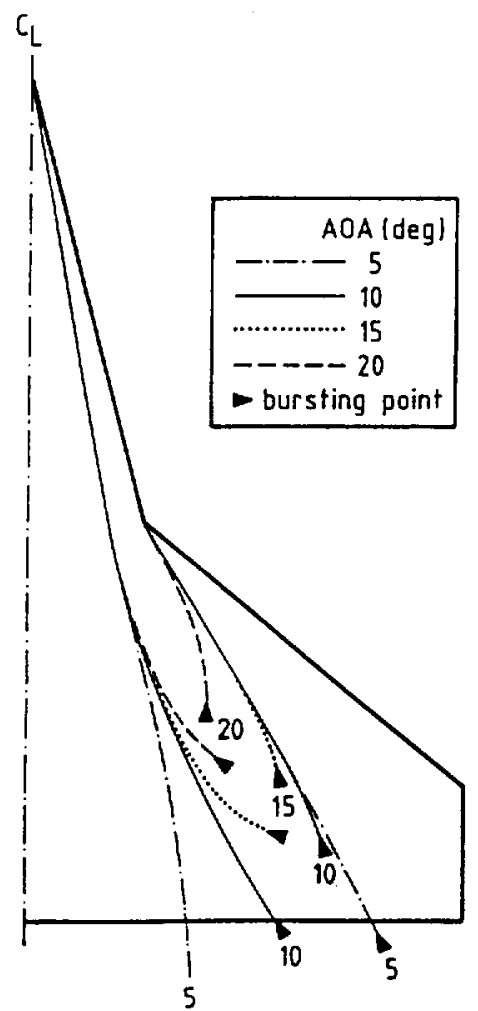

Figure 5: Effect of angle of attack on vortex axes trajectories

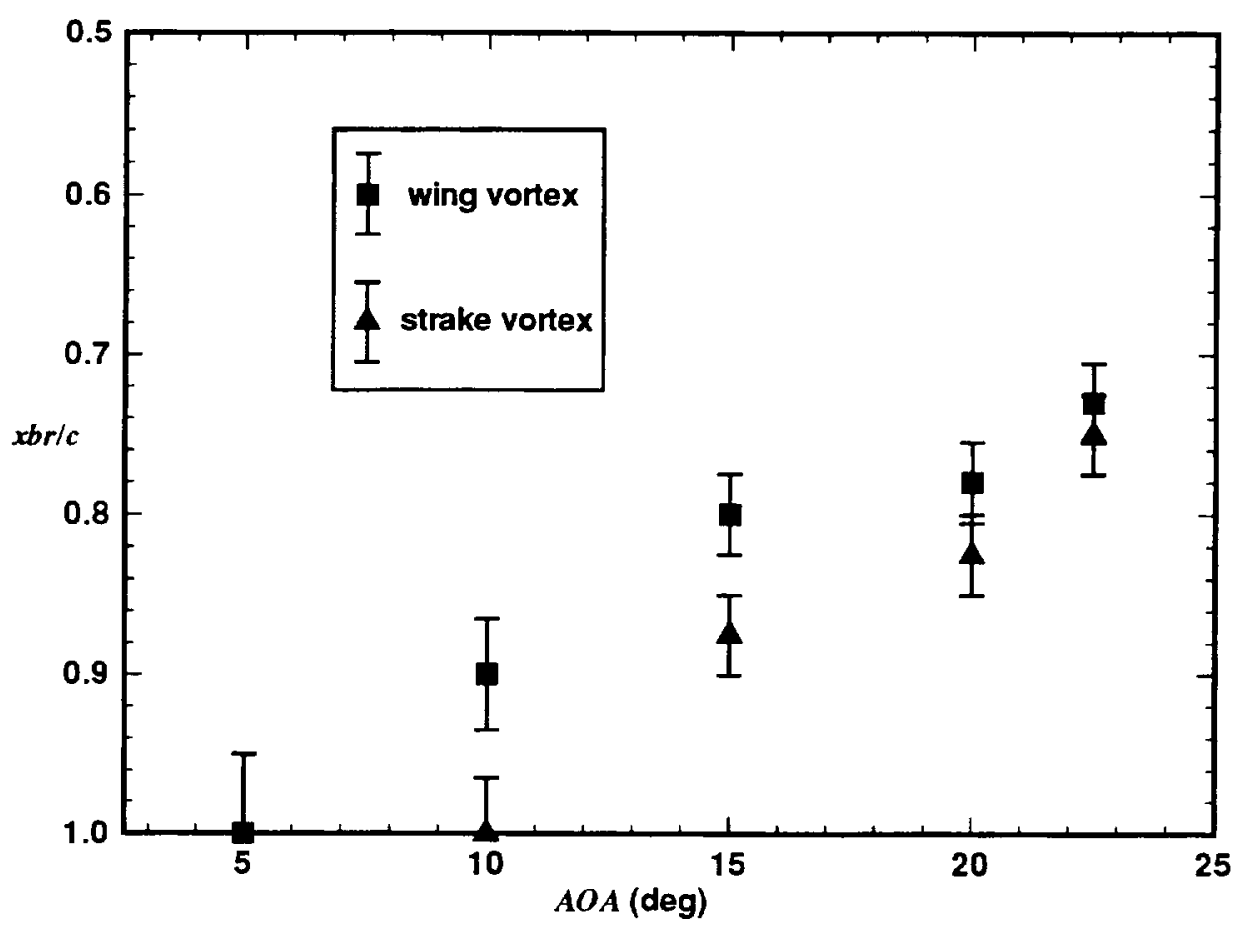

Figure 6: Effect of angle of attack on vortex core bursting locations 


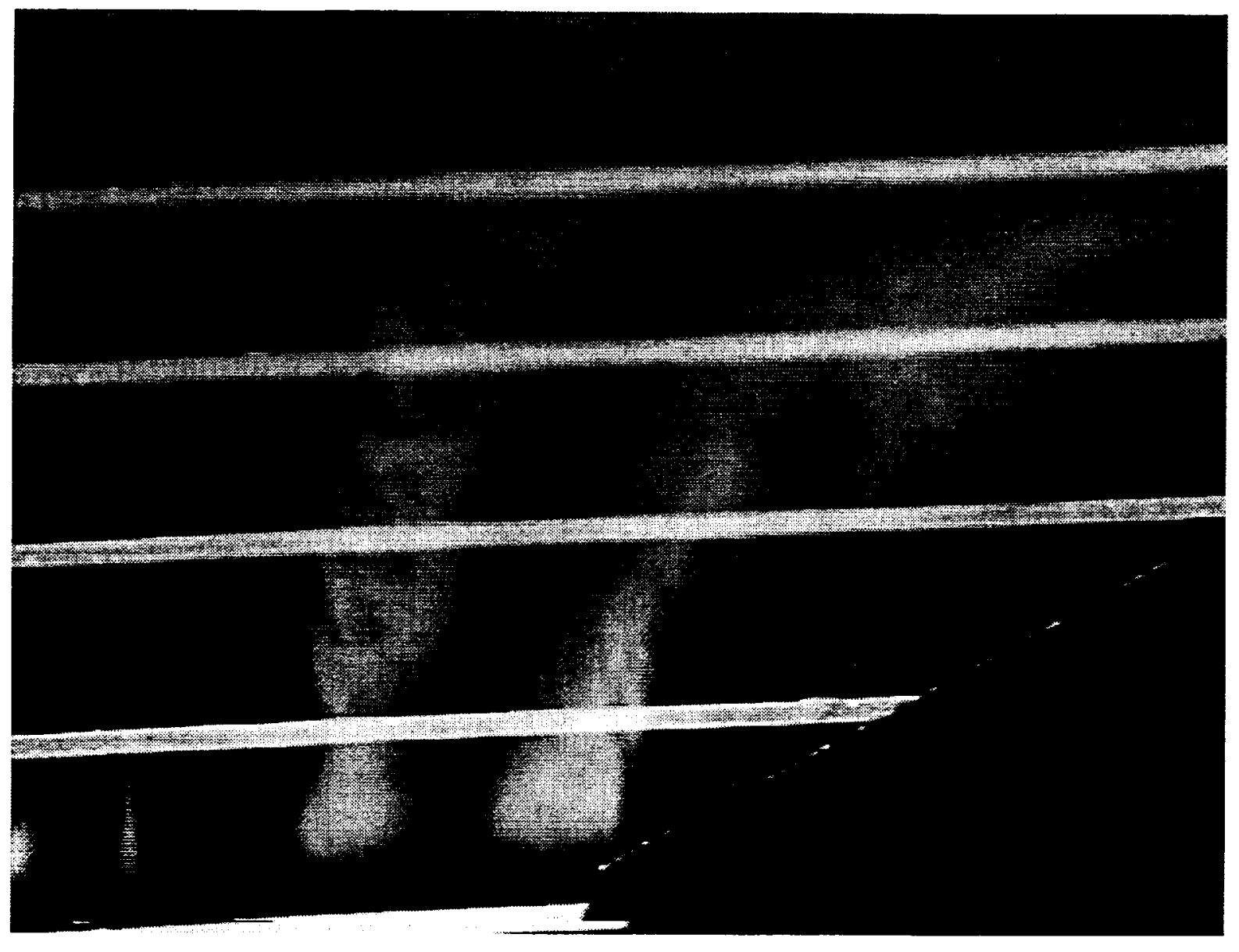

Figure 7: Vortical flow structure in free shear layer of strake vortex; $A O A=20 \mathrm{deg}$

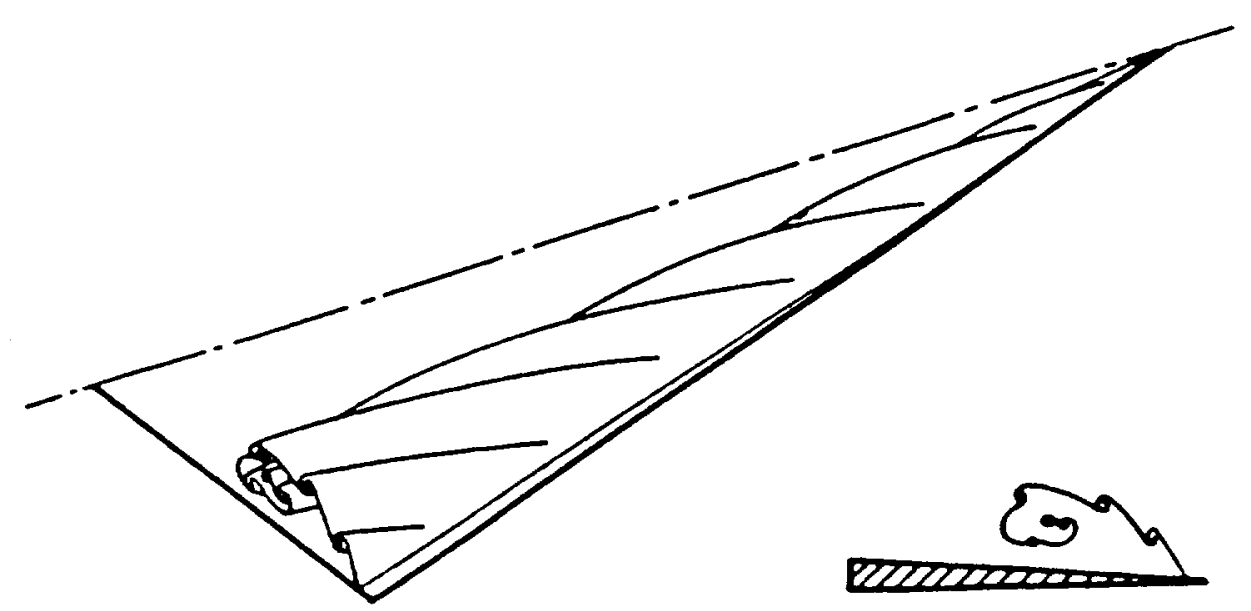

Figure 8: Diagram of streamwise vortices in free shear layer (Squire, Ref.19) 


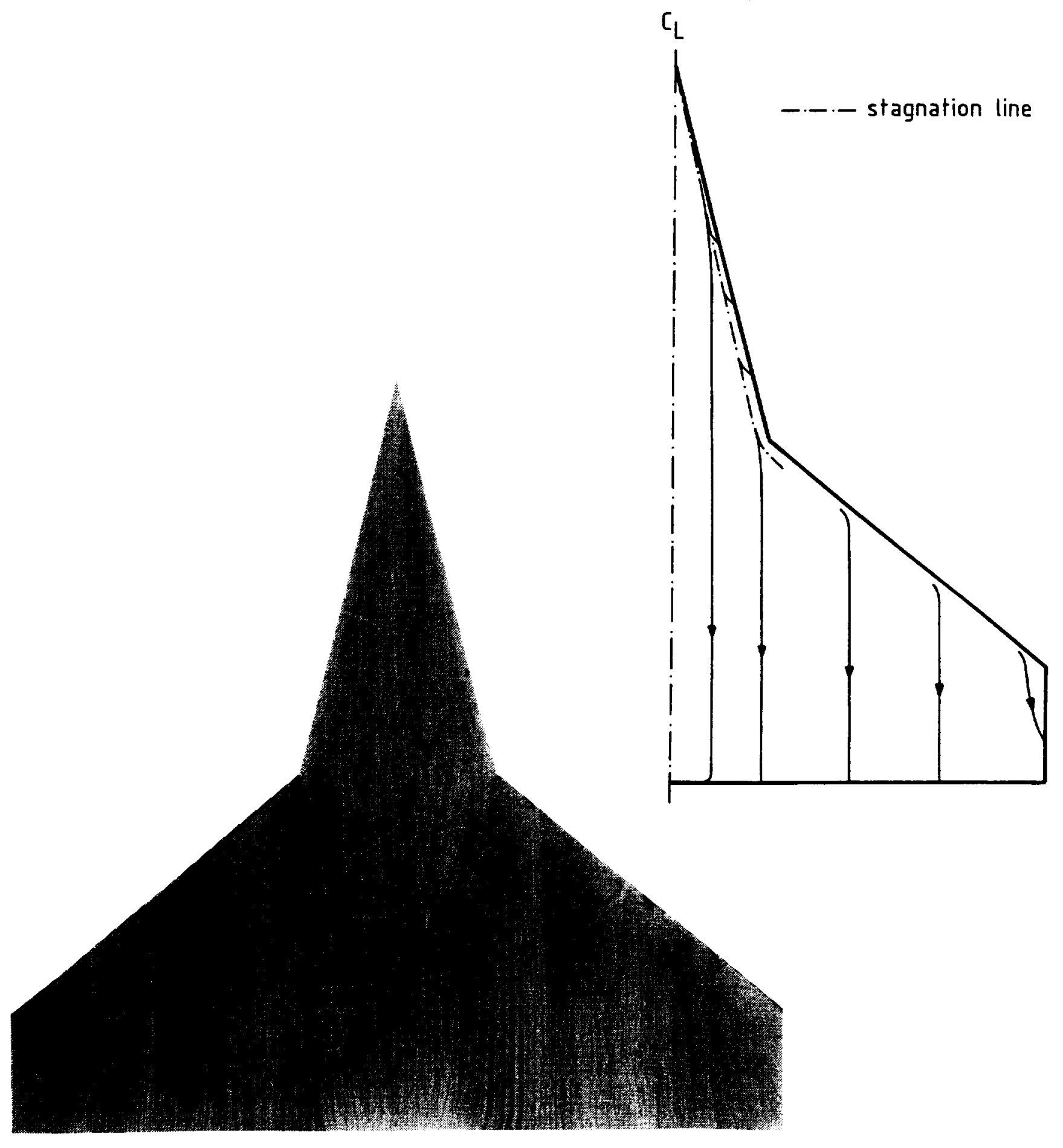

Figure 9(a): Upper surface flow pattern; $A O A=-10 \mathrm{deg}$ 


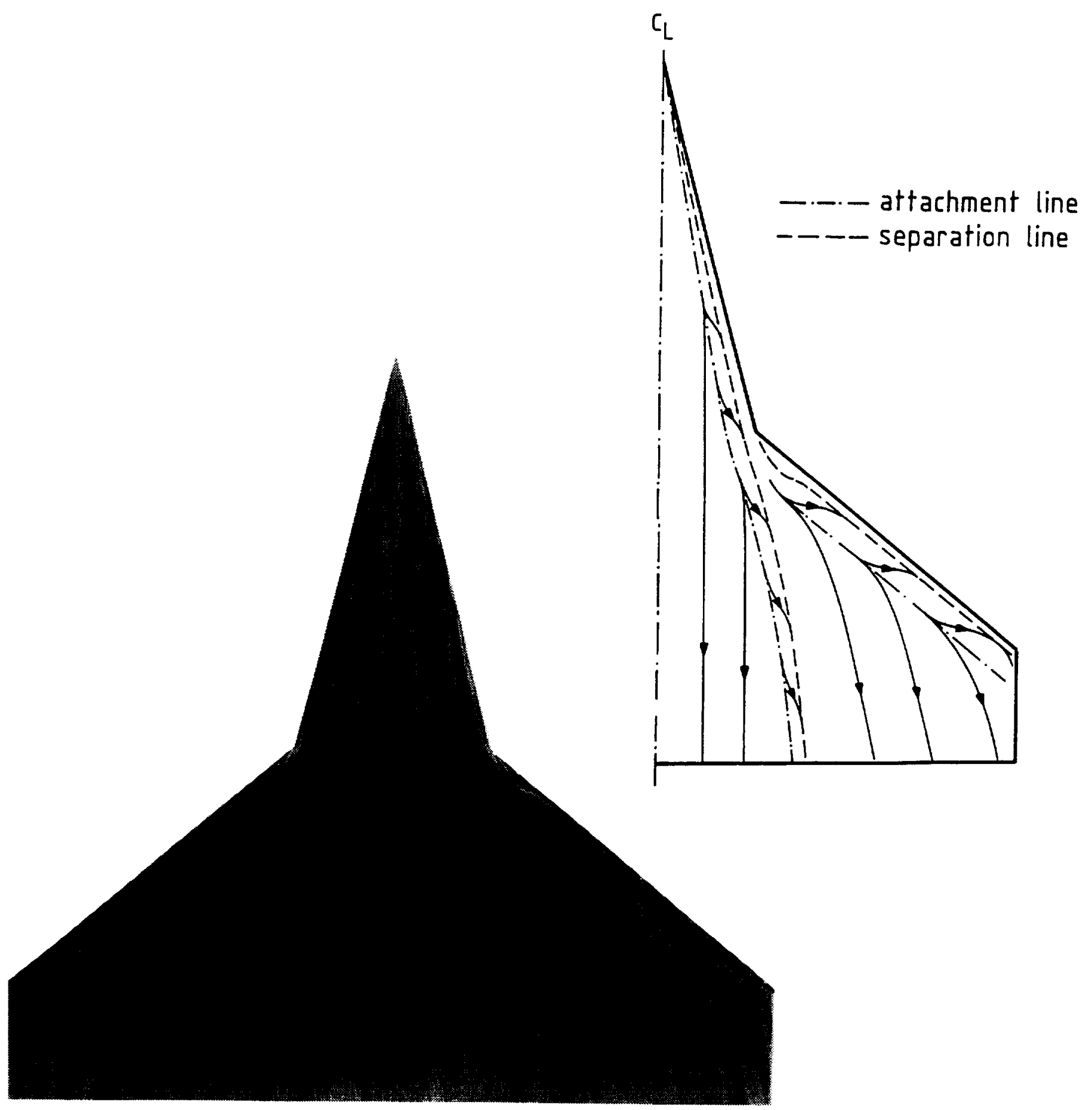

Fignre 9(b): Continued; $A O A=0 \mathrm{deg}$ 


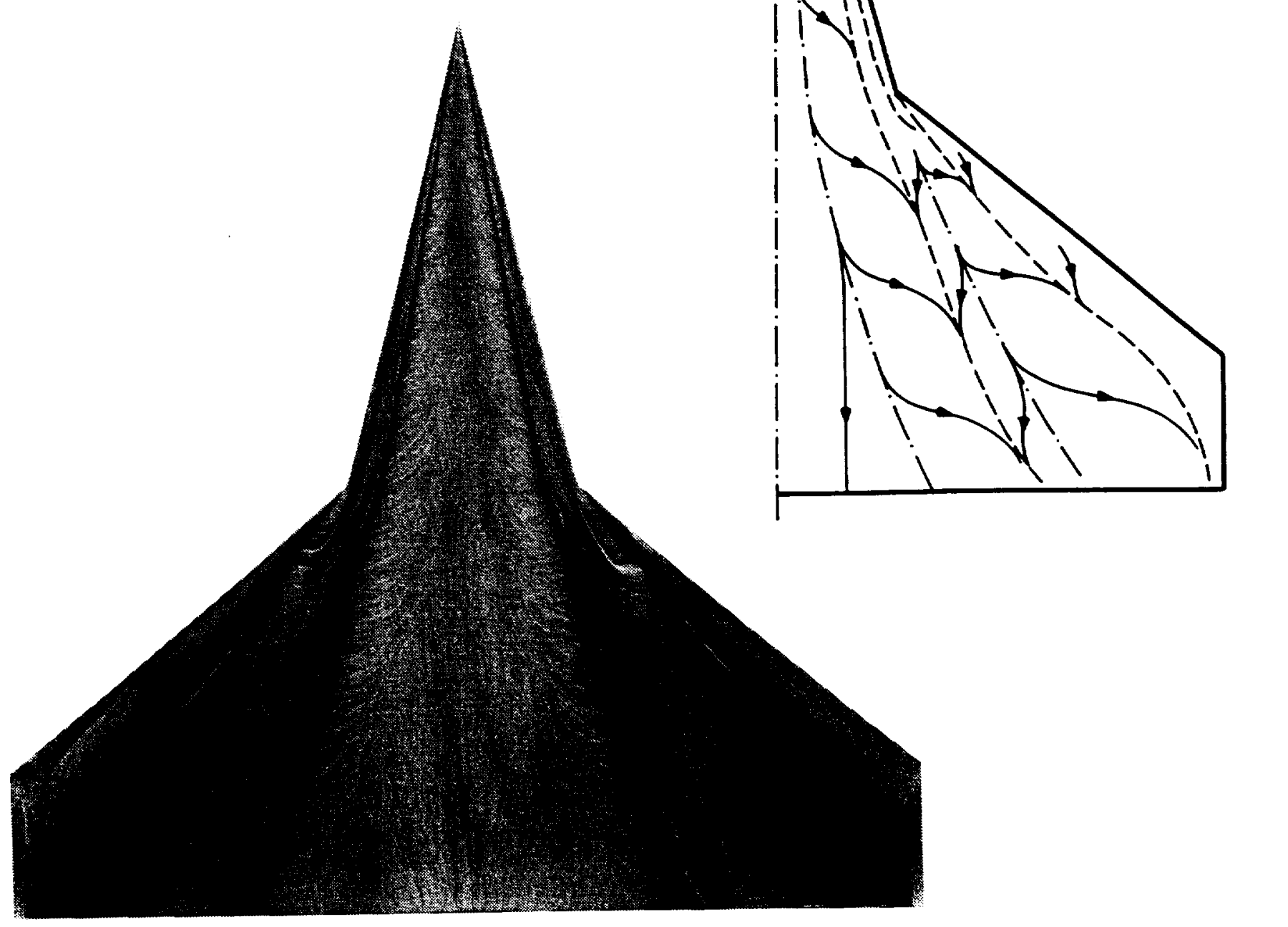

Figure 9(c): Continued; $A O A=10 \mathrm{deg}$ 


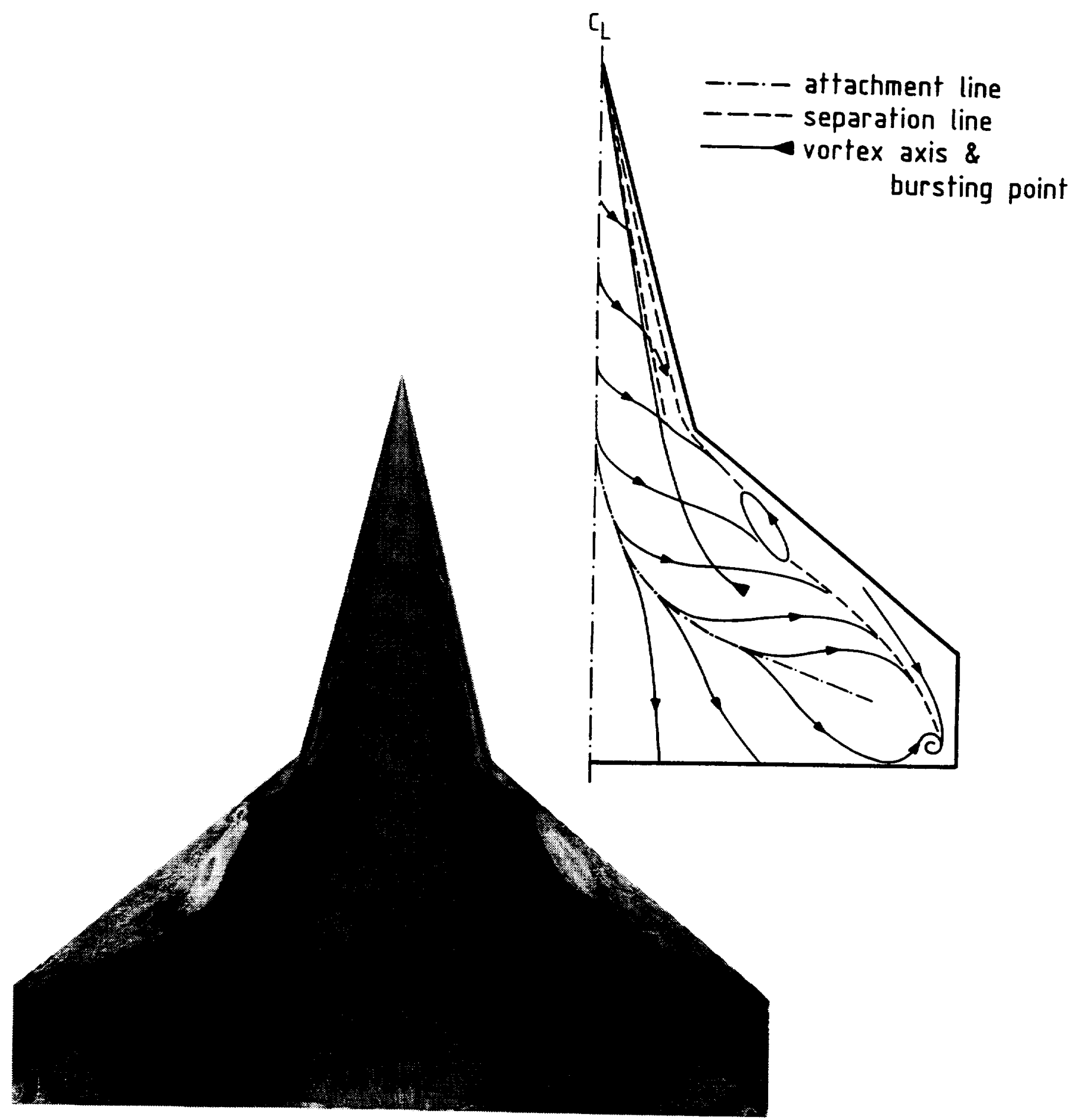

Figure 9(d): Concluded; $A O A=22.5 \mathrm{deg}$ 


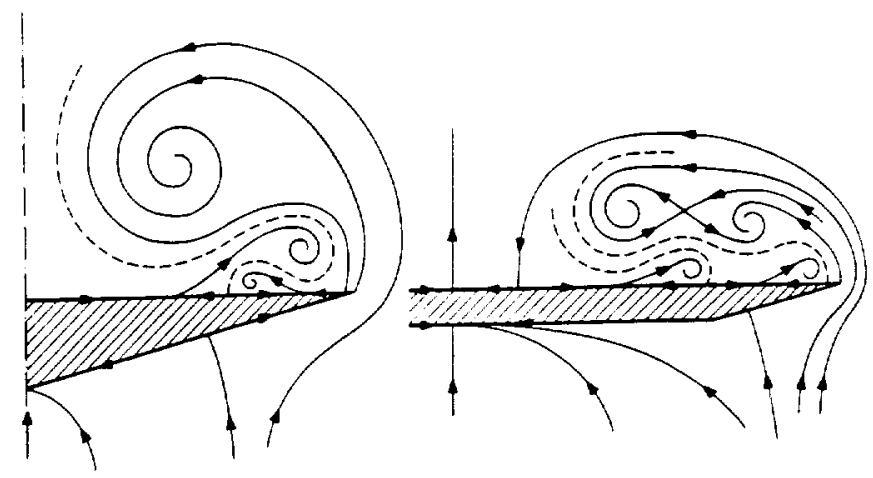

Figure 10: Topology of crossflow over strake (left) and wing (right sketch)

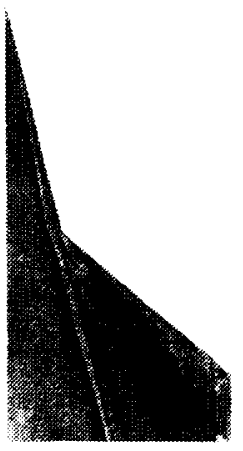

$R e=0.5 \mathrm{M}$

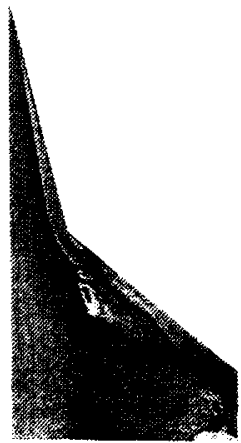

$R e=0.5 \mathrm{M}$

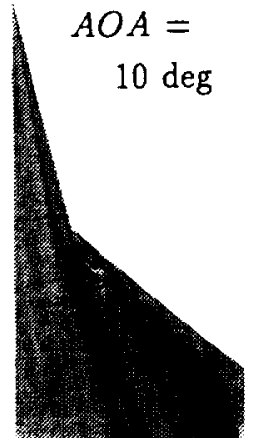

$1.0 \mathrm{M}$

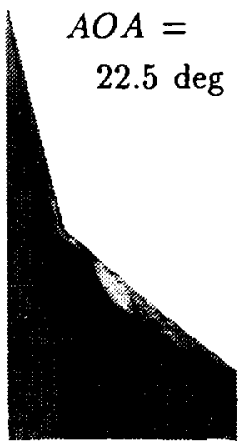

$1.0 \mathrm{M}$

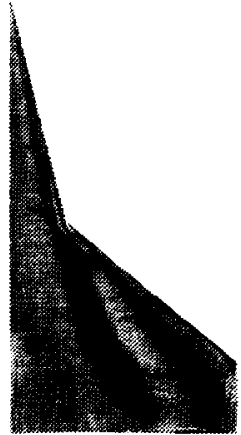

$1.5 \mathrm{M}$

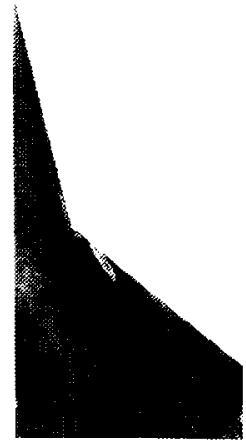

$1.5 \mathrm{M}$

Figure 11: Effect of Reynolds number on surface flow pattern: $A O A=10$ and $22.5 \mathrm{deg}$ 


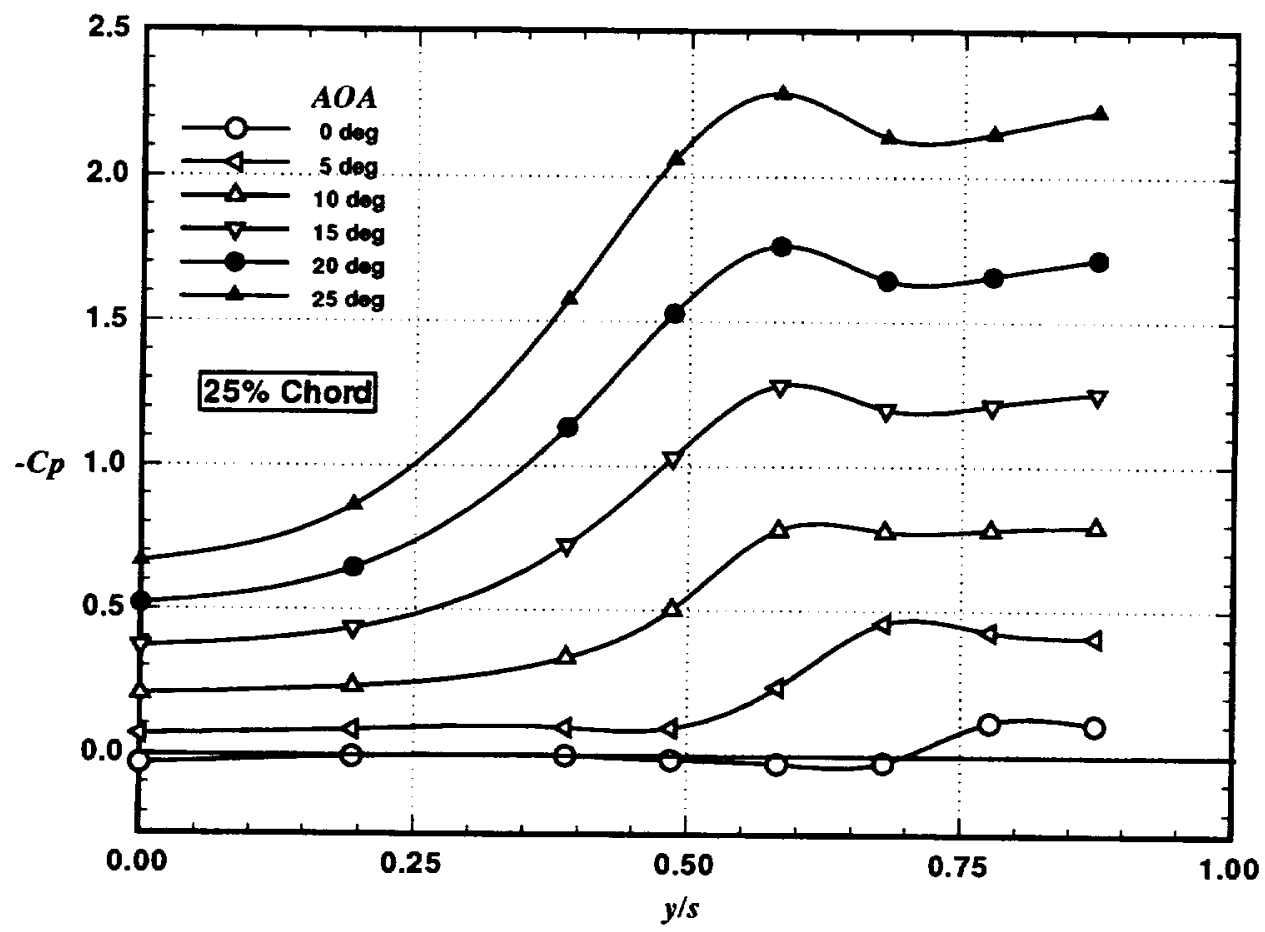

Figure 12: Effect of angle of attack on upper surface $C p$ at $25 \%$ chord; $R e=1.0 \mathrm{M}$

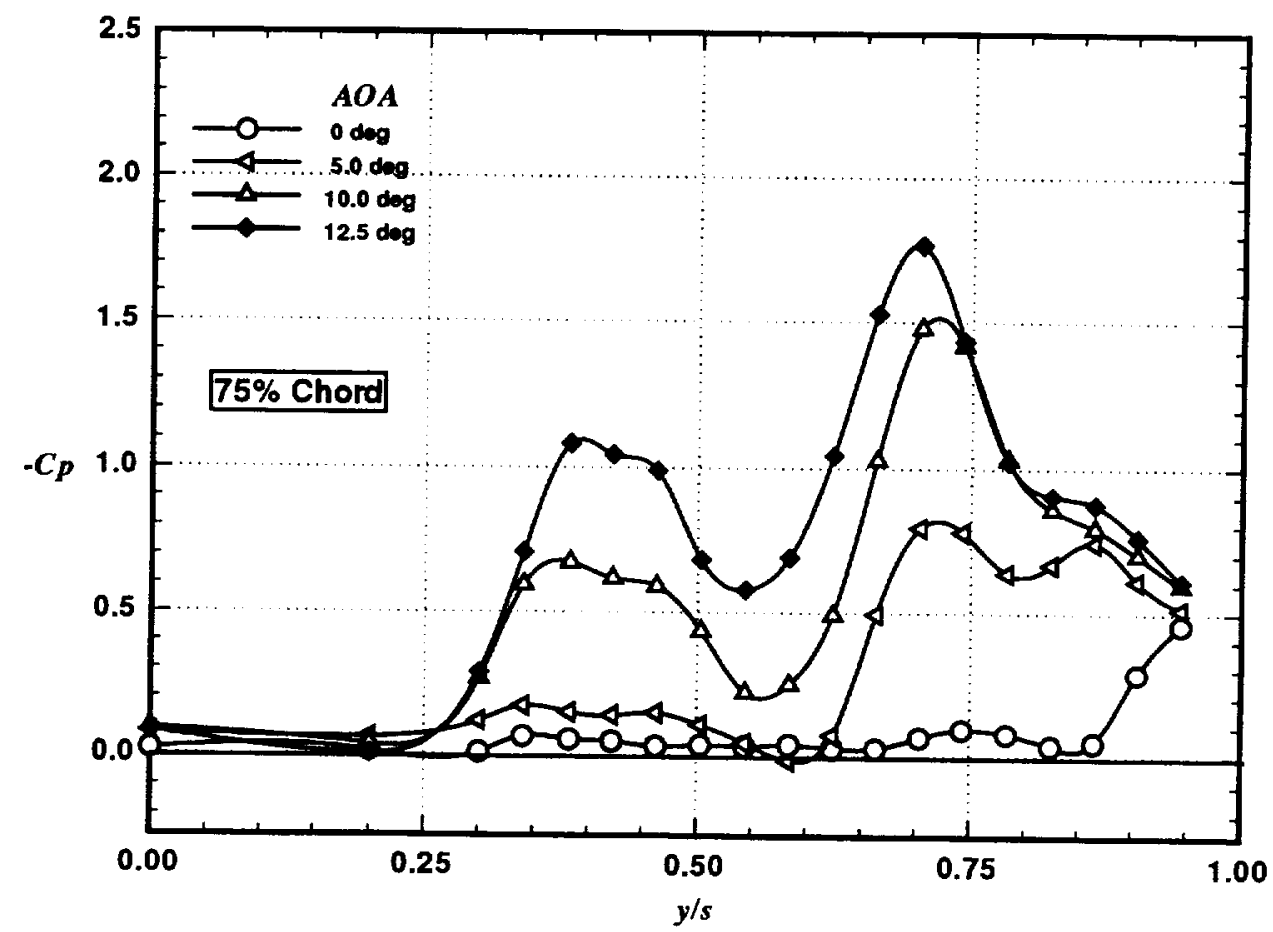

Figure 13(a): Effect of angle of attack on upper surface $C p$ at $75 \%$ chord; $R e=1.0 \mathrm{M}$ 


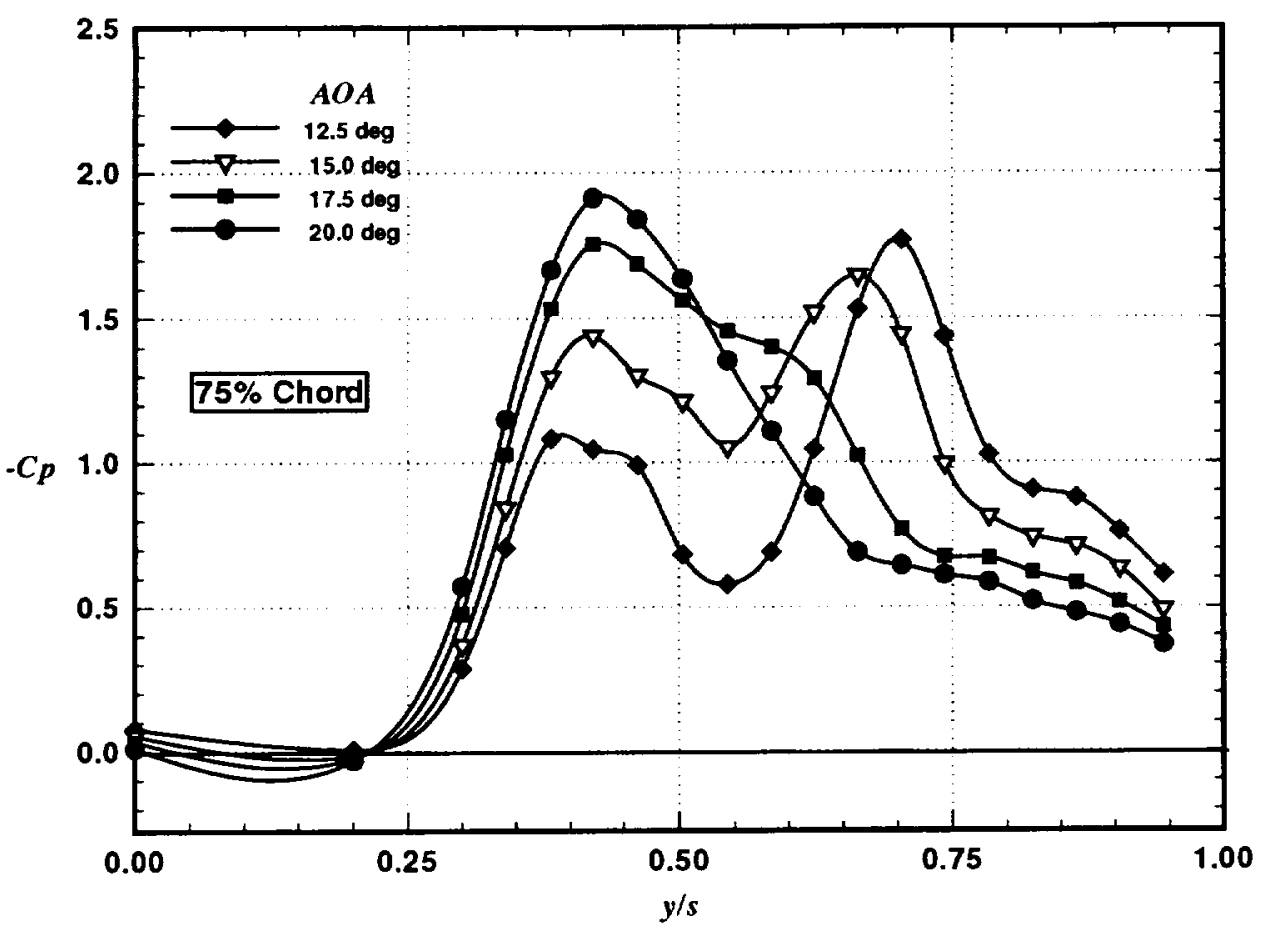

Figure 13(b): Continued

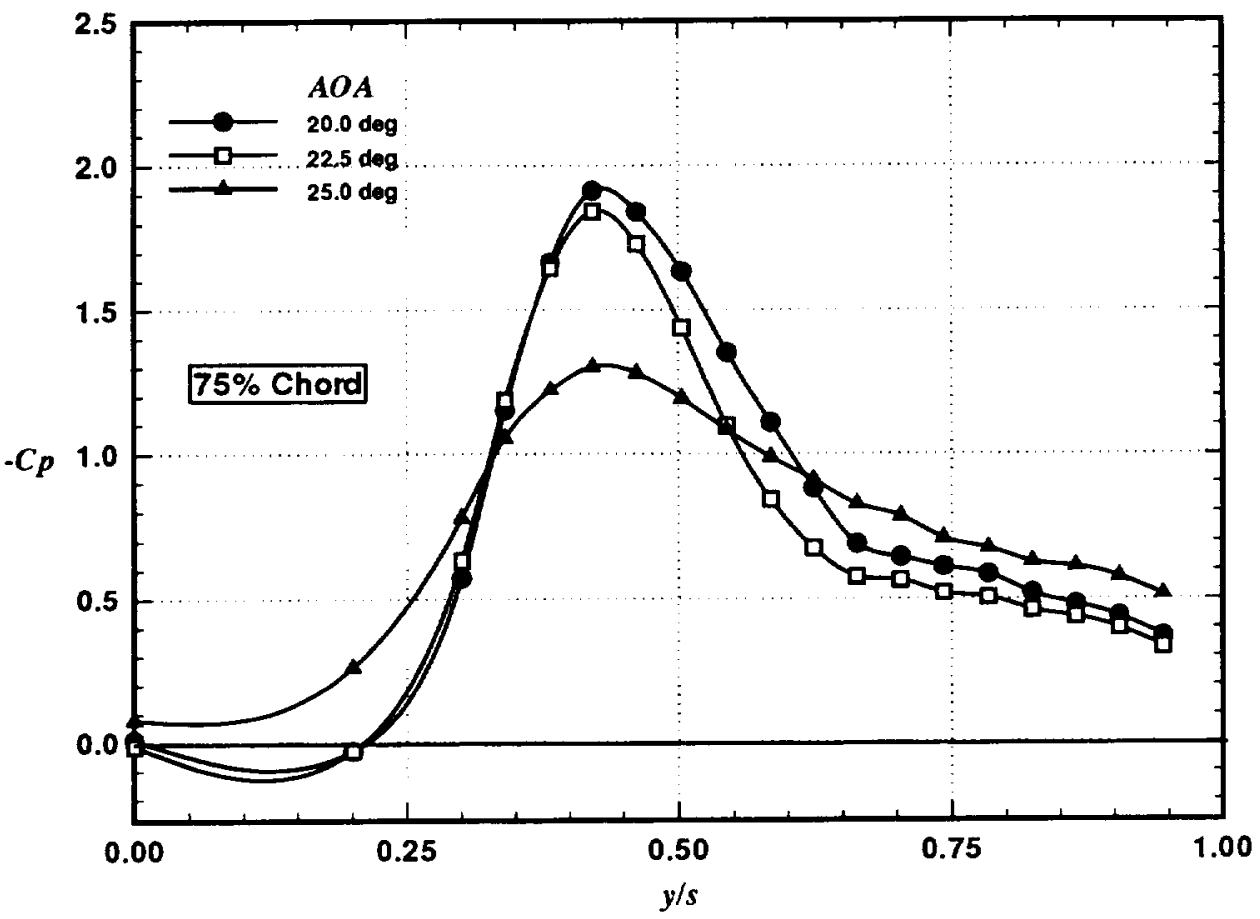

Figure 13(c): Concluded 


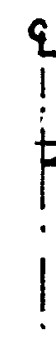

$q$

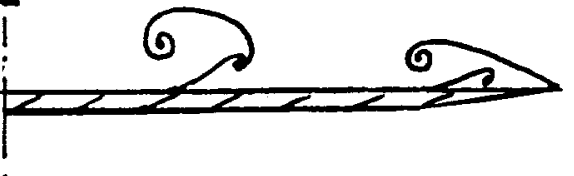

AOA (deg)

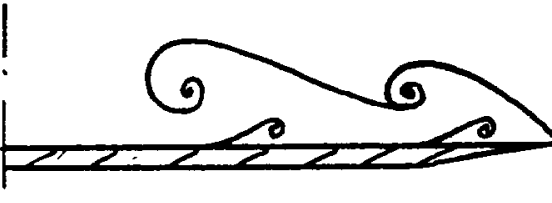

10
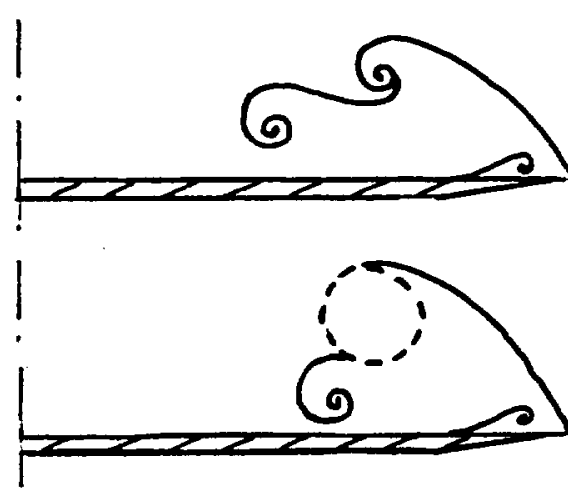

15

Figure 14: Effect of angle of attack on the topology of the crossflow at $75 \%$ chord

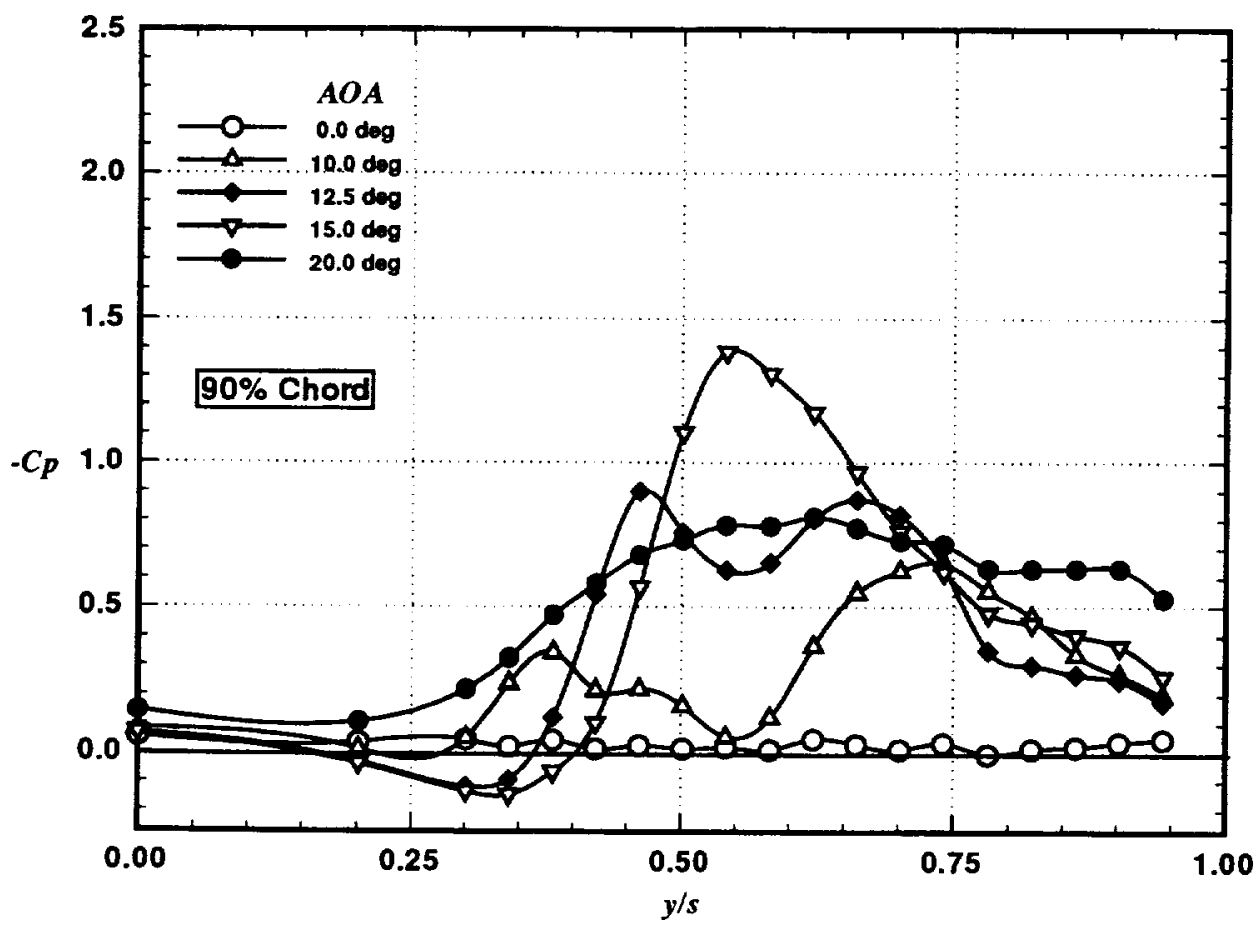

Figure 15: Effect of angle of attack on upper surface $C p$ at $90 \%$ chord; $R e=1.0 \mathrm{M}$ 

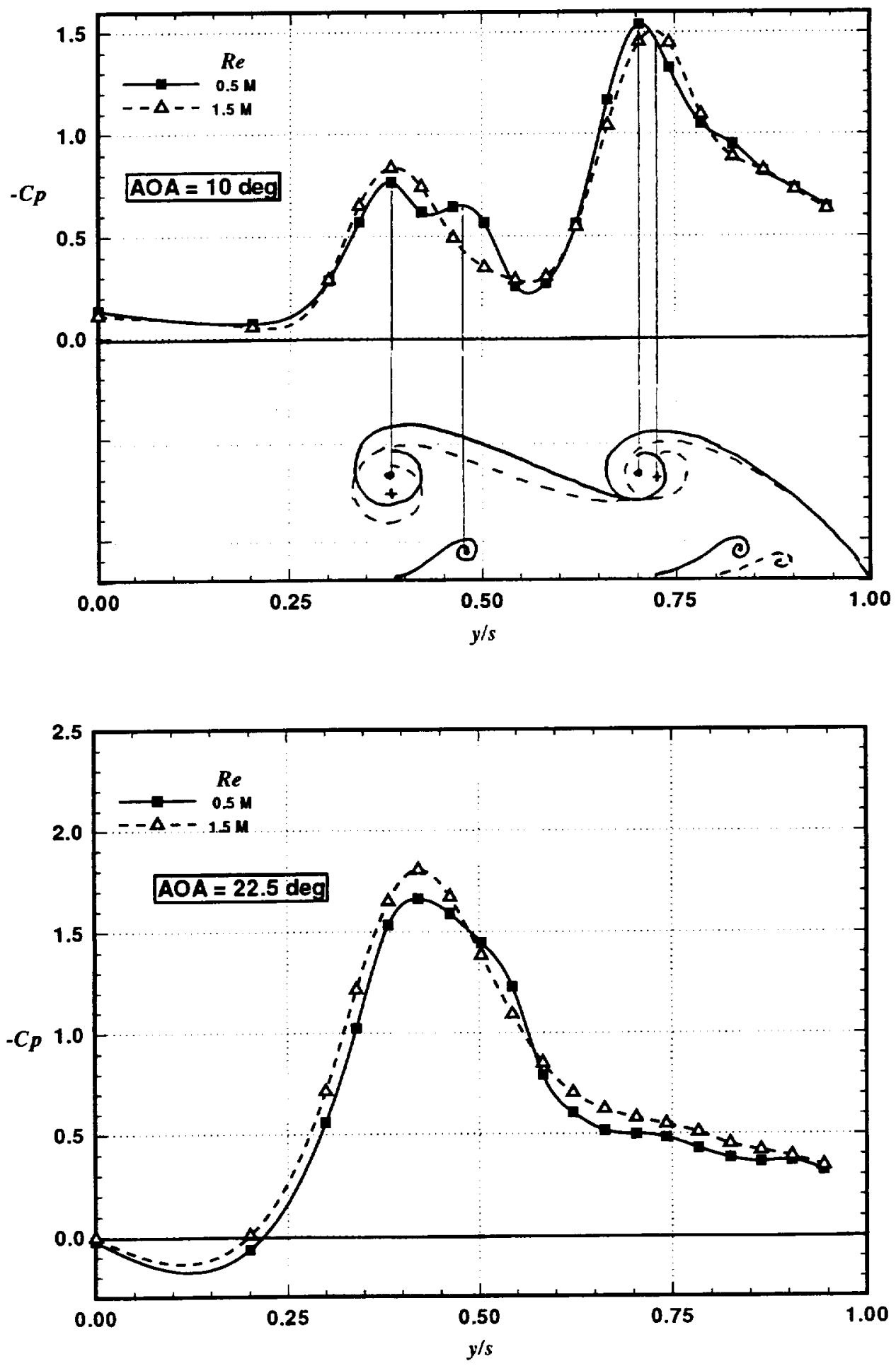

Figure 16: Reynolds number effect on upper surface $C p$ at $75 \%$ chord; $A O A=10$ and $22.5 \mathrm{deg}$ 


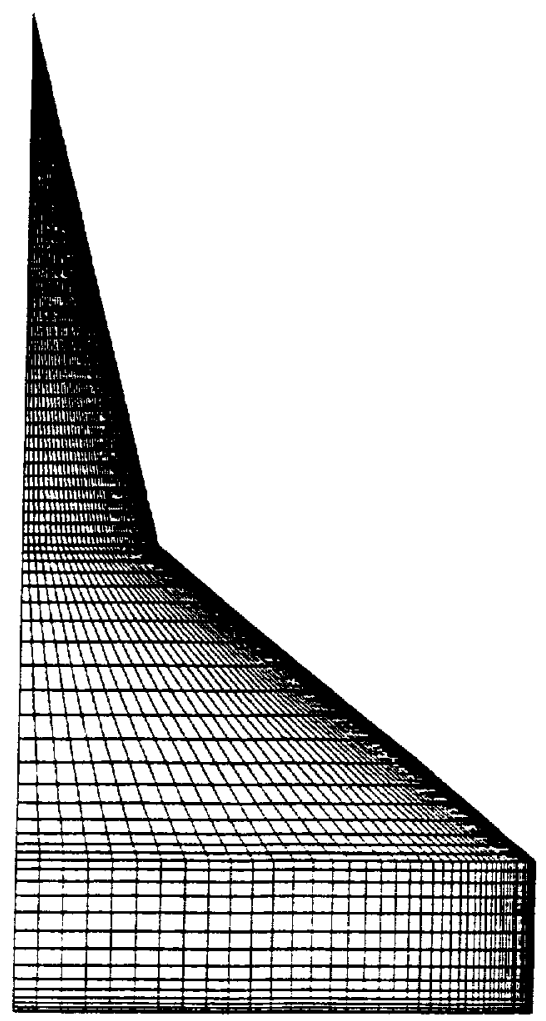

Figure 17: Surface grid

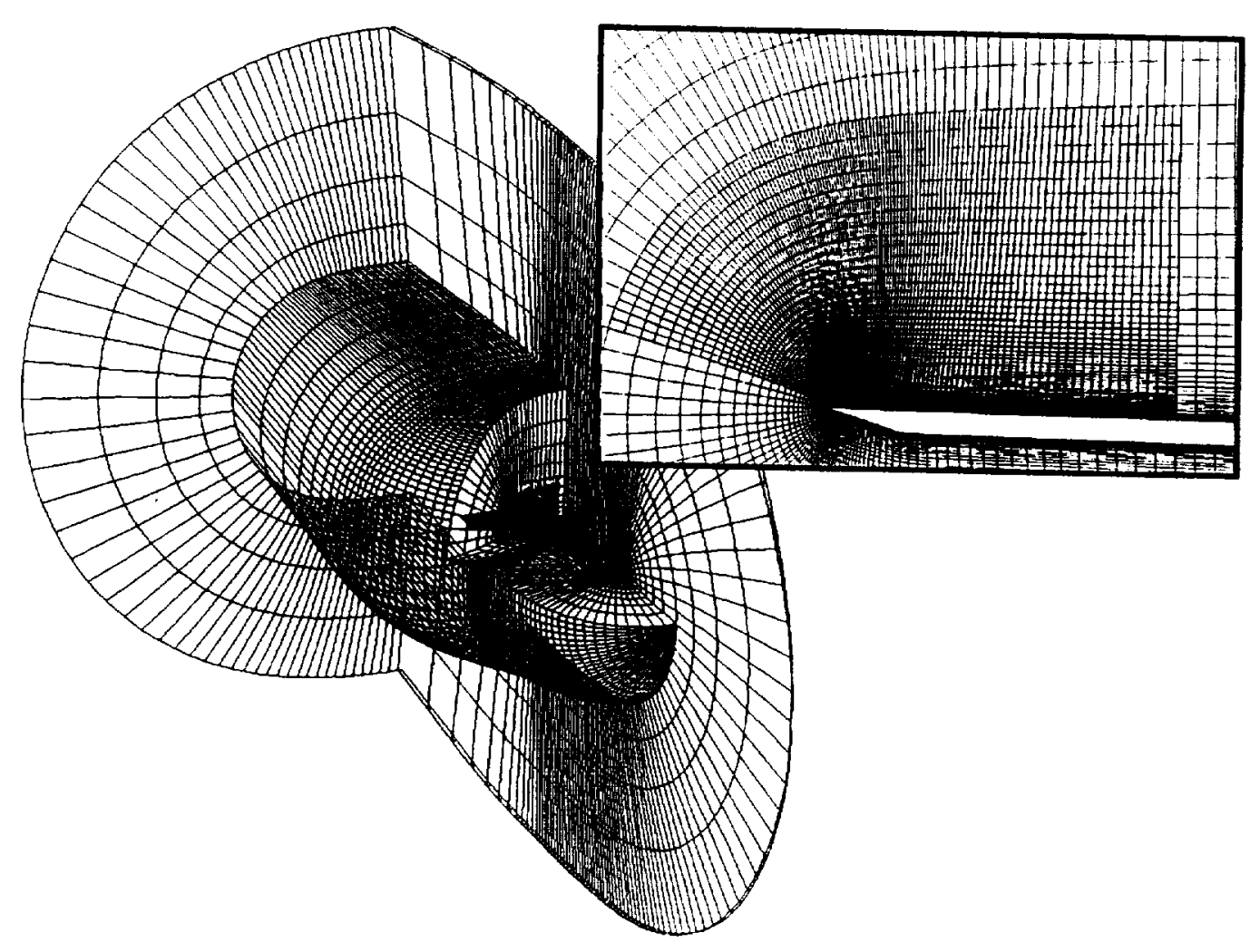

Figure 18: Field grid 

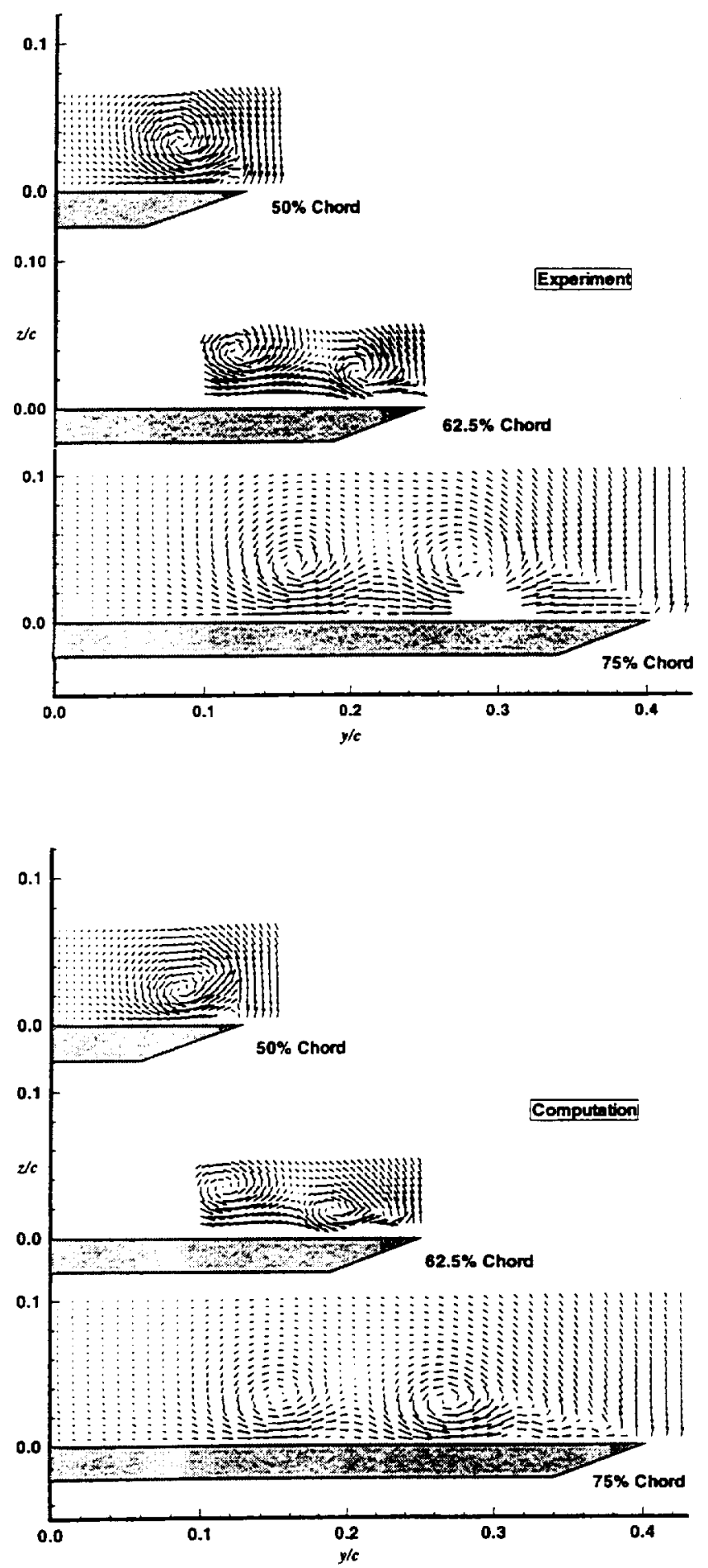

Figure 19: Measured and computed velocity vectors at $A O A=10 \mathrm{deg}$ 

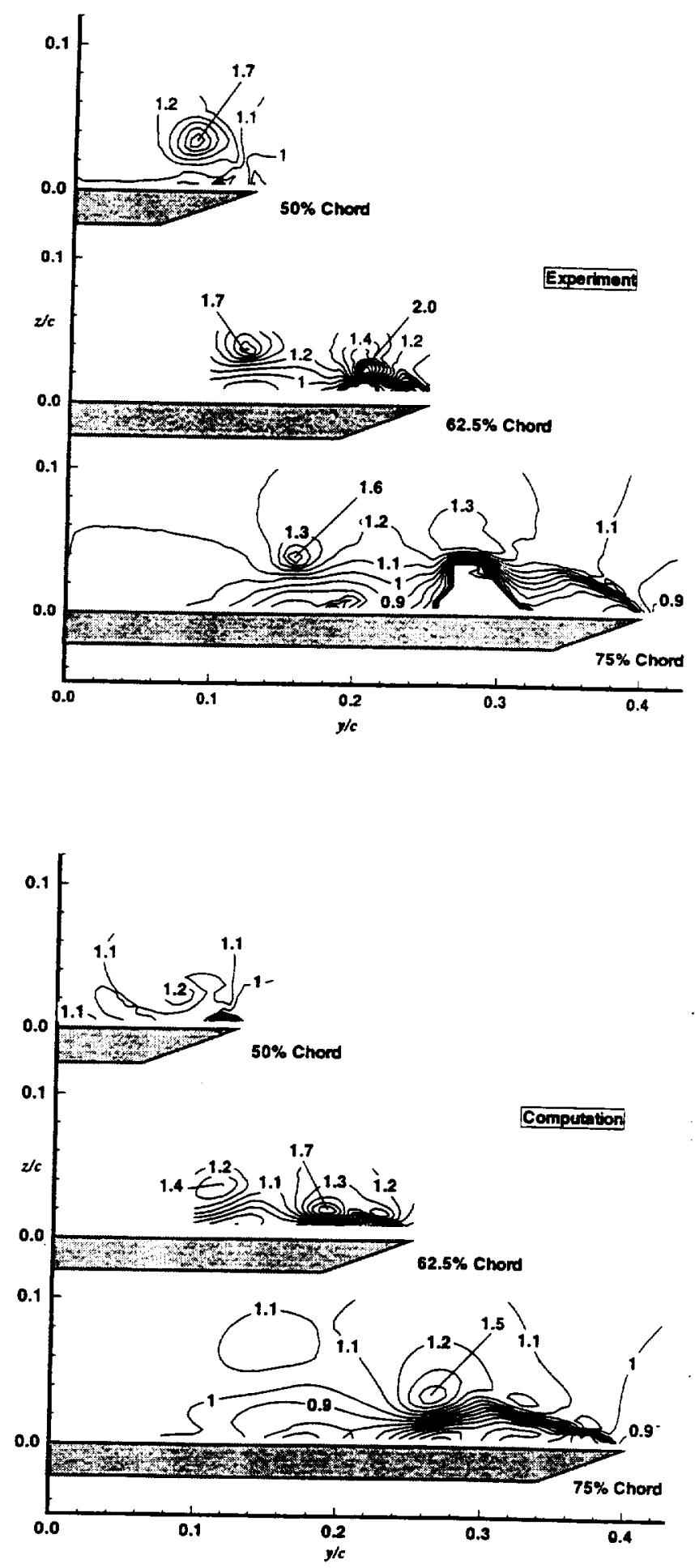

Figure 20: Measured and computed $u / U_{\infty}$ at $A O A=10 \mathrm{deg}$ 

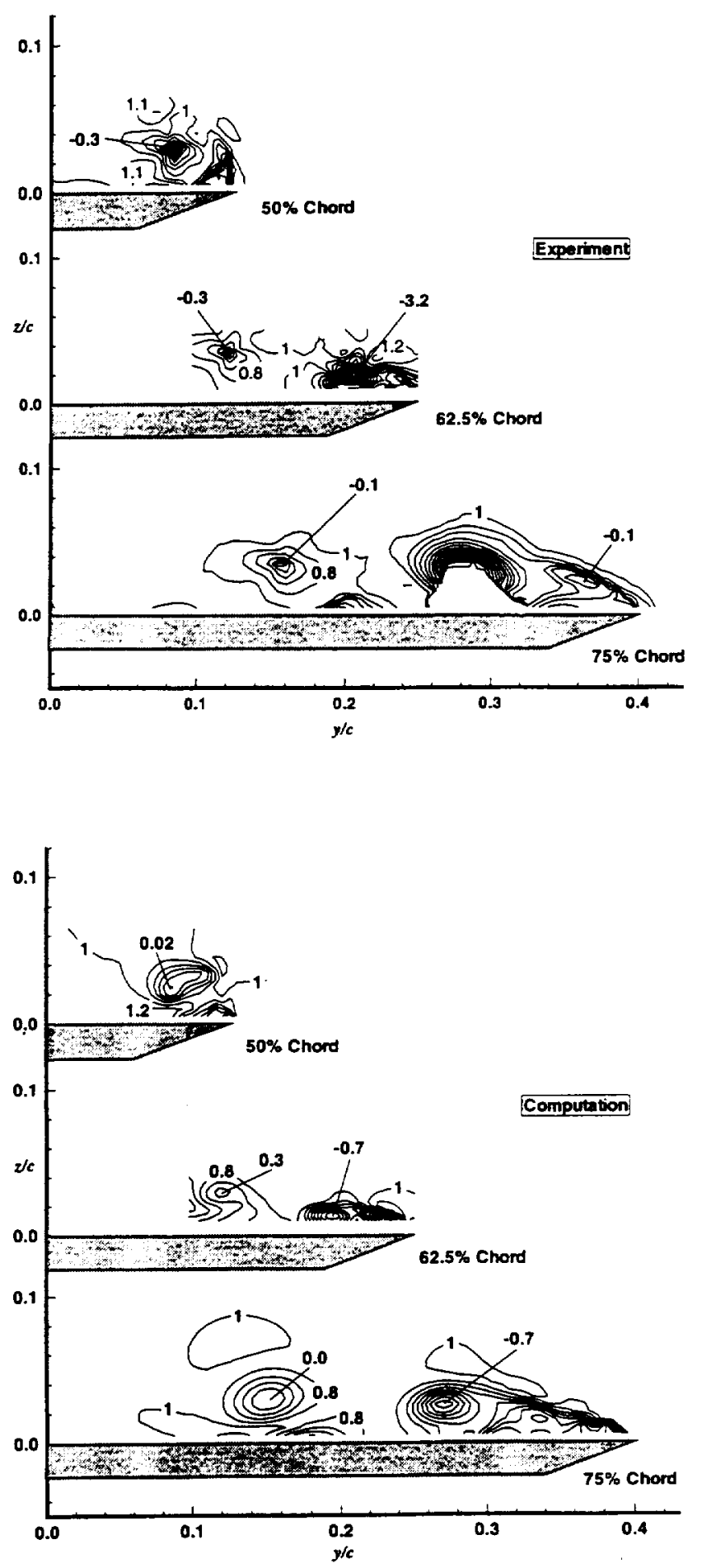

Figure 21: Measured and computed $C p_{t}$ at $A O A=10 \mathrm{deg}$ 

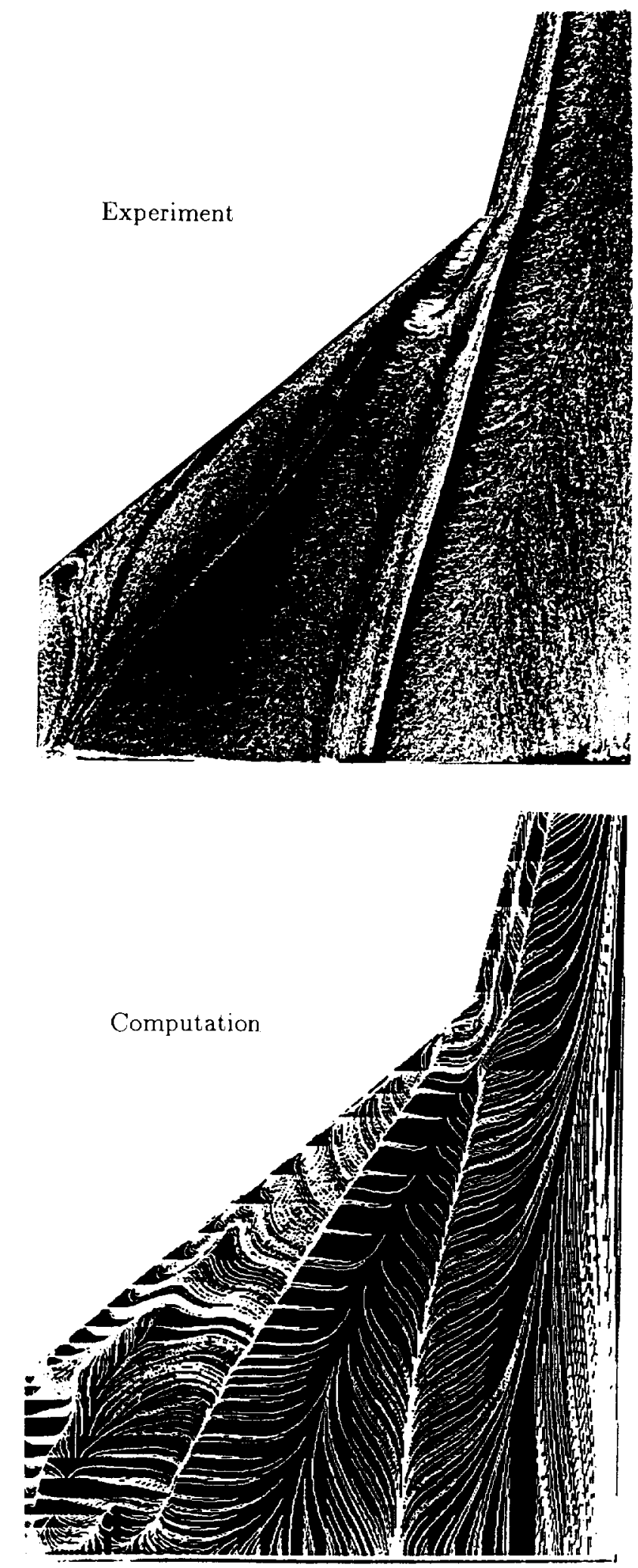

Figure 22: Experimental and computed surface flow pattern at $A O A=10 \mathrm{deg}:$ Re $=0.5 \mathrm{M}$ 


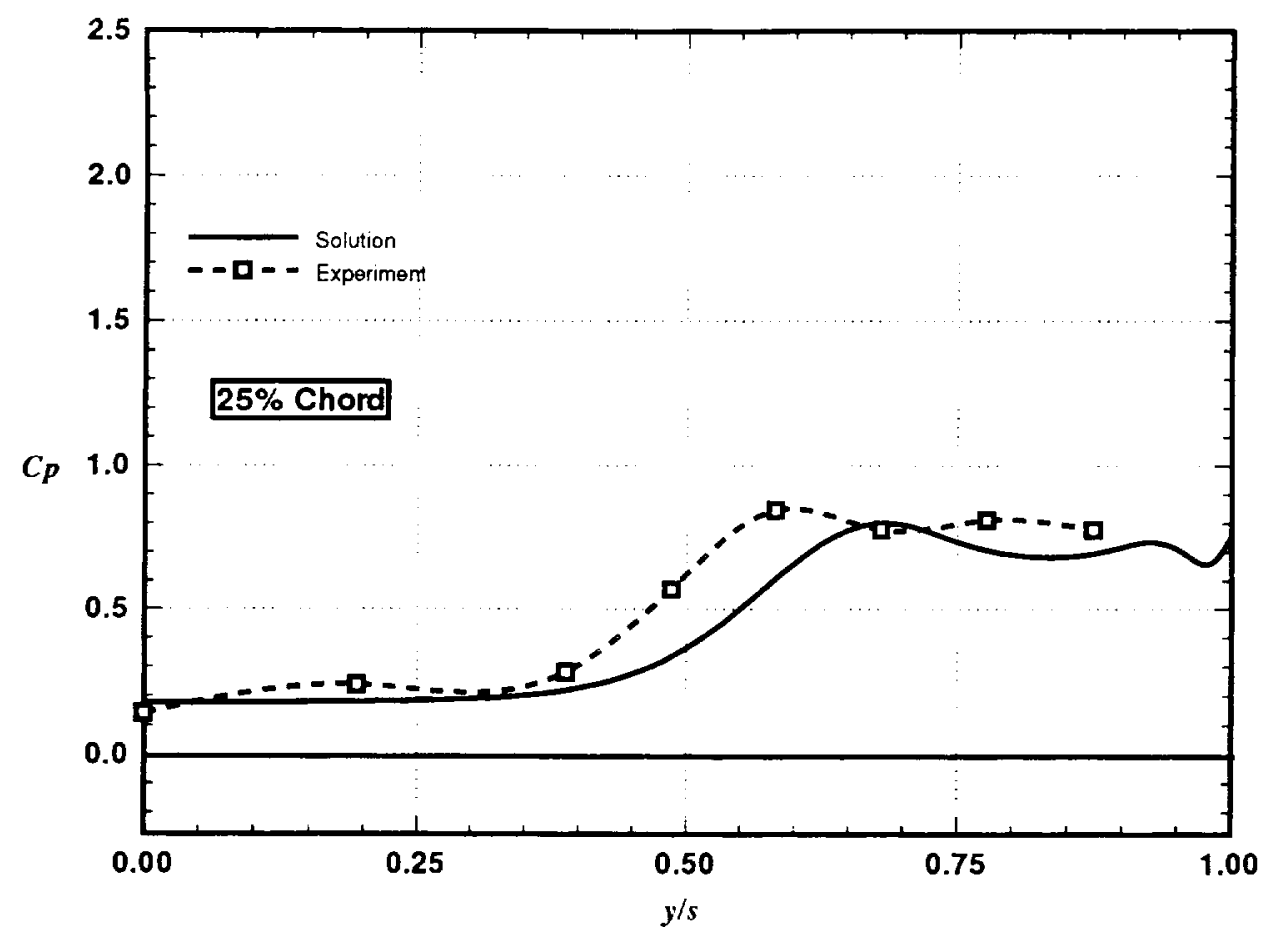

Figure 23(a): Comparison of measured and computed upper surface $(\mathrm{p}$ at $25 \%$ chord: $A O A=10 \mathrm{deg}: R \epsilon=0.5 \mathrm{M}$

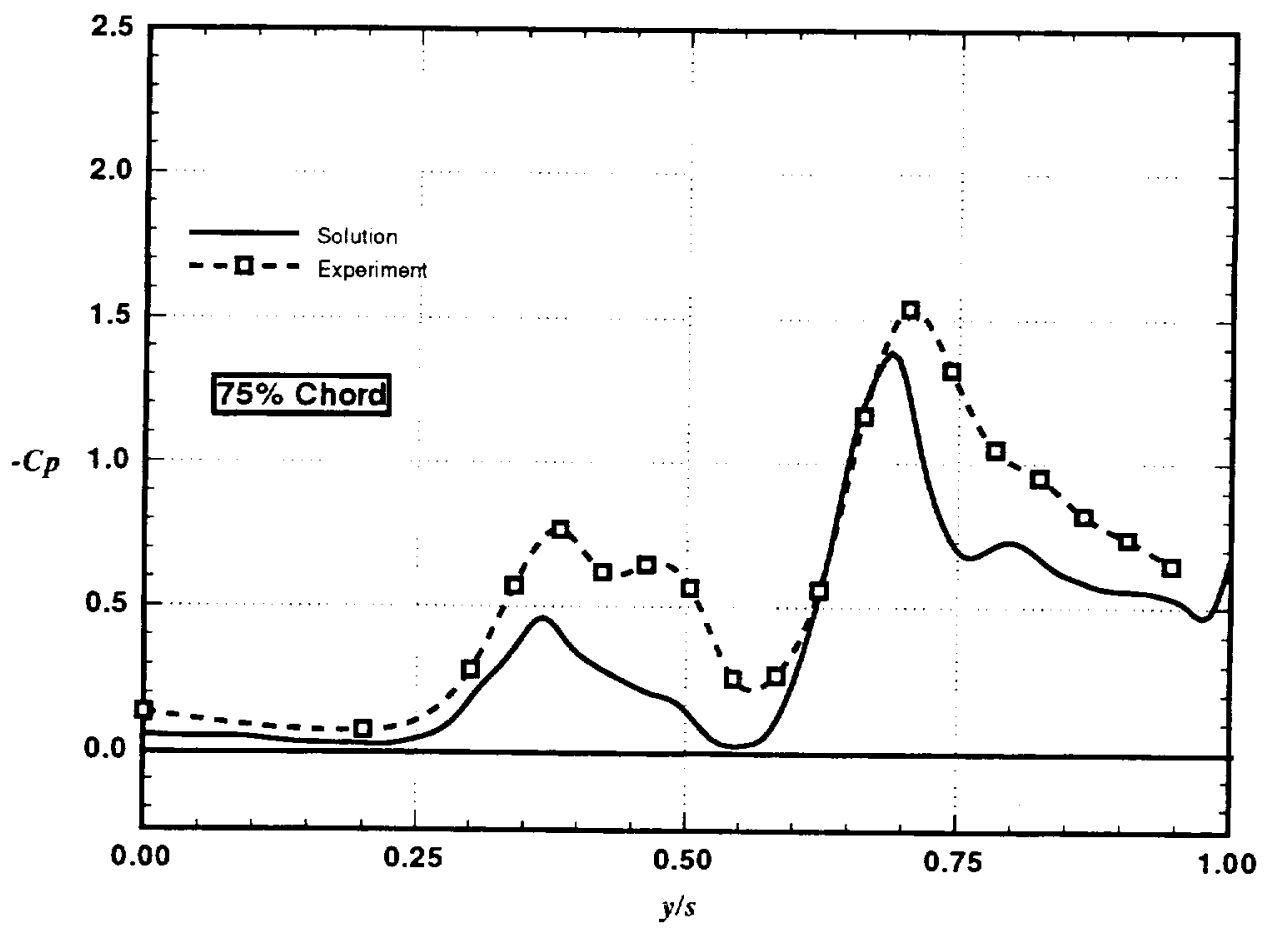

Figure 23(b): Continued; $C p$ at $55 \%$ chord 


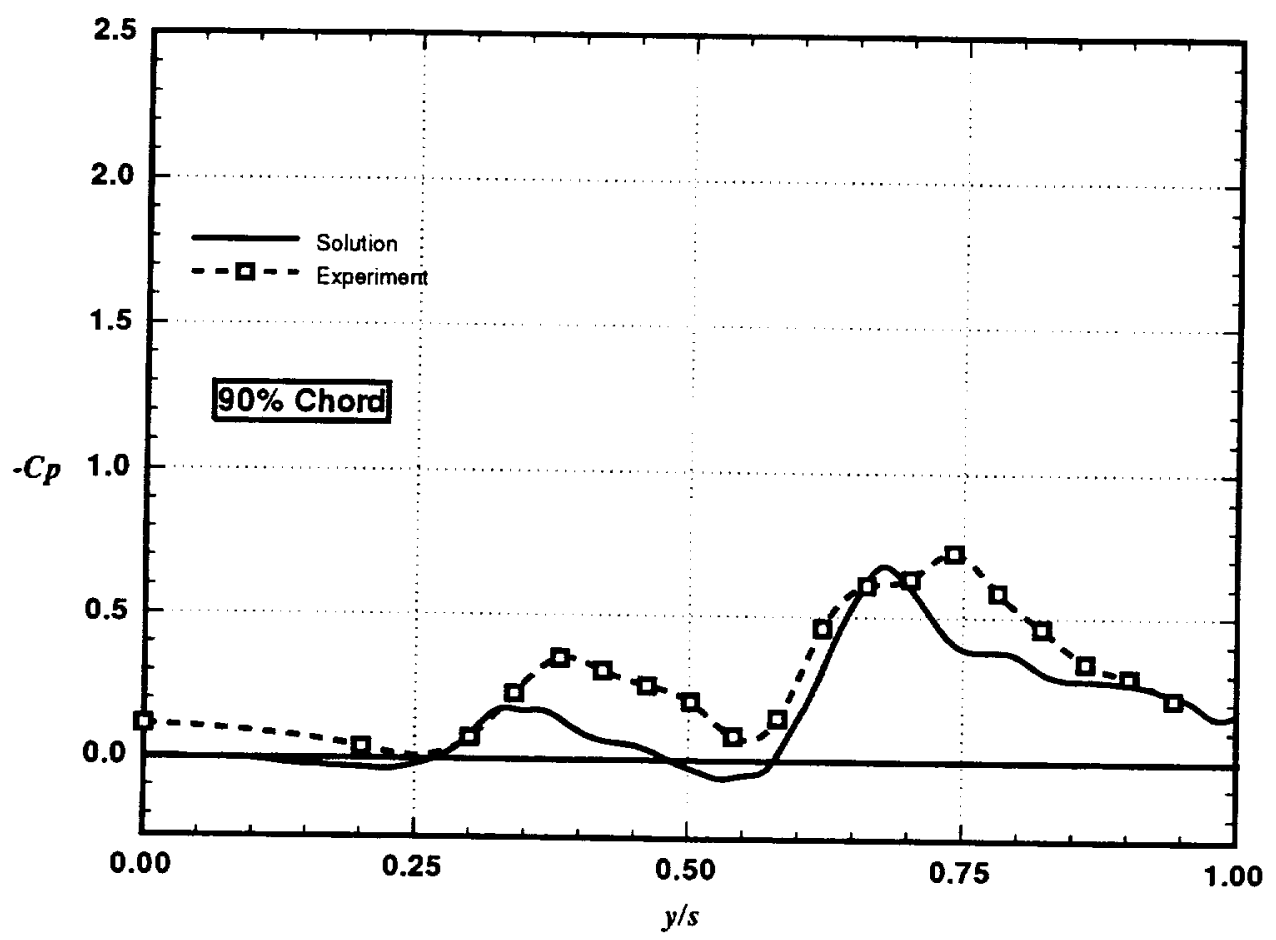

Figure 23(c): Concluded; $C p$ at $90 \%$ chord

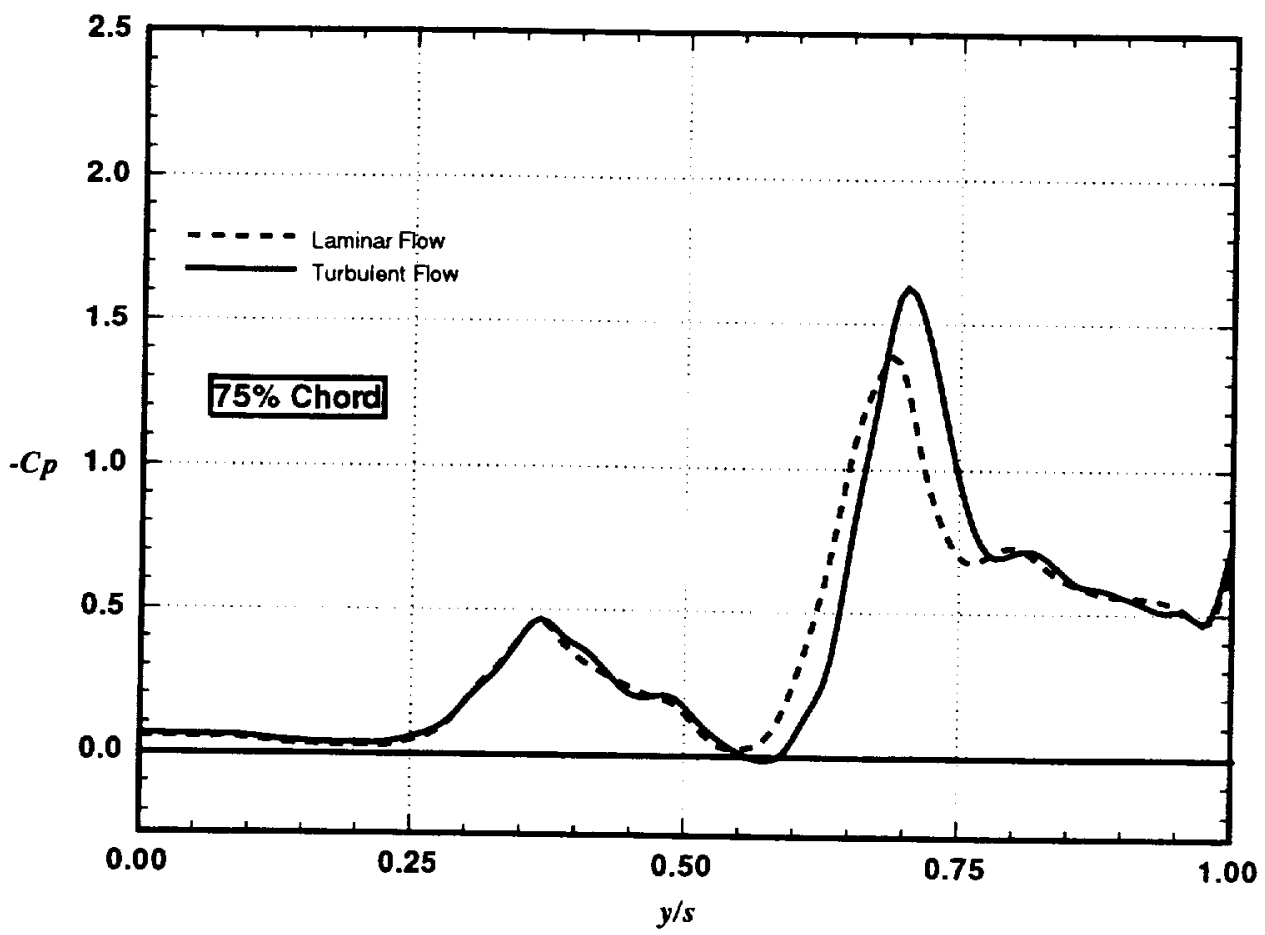

Figure 24: Comparison of laminar and turbulent flow solution for upper surface $C p$ at $A O A=10 \operatorname{deg}$ 

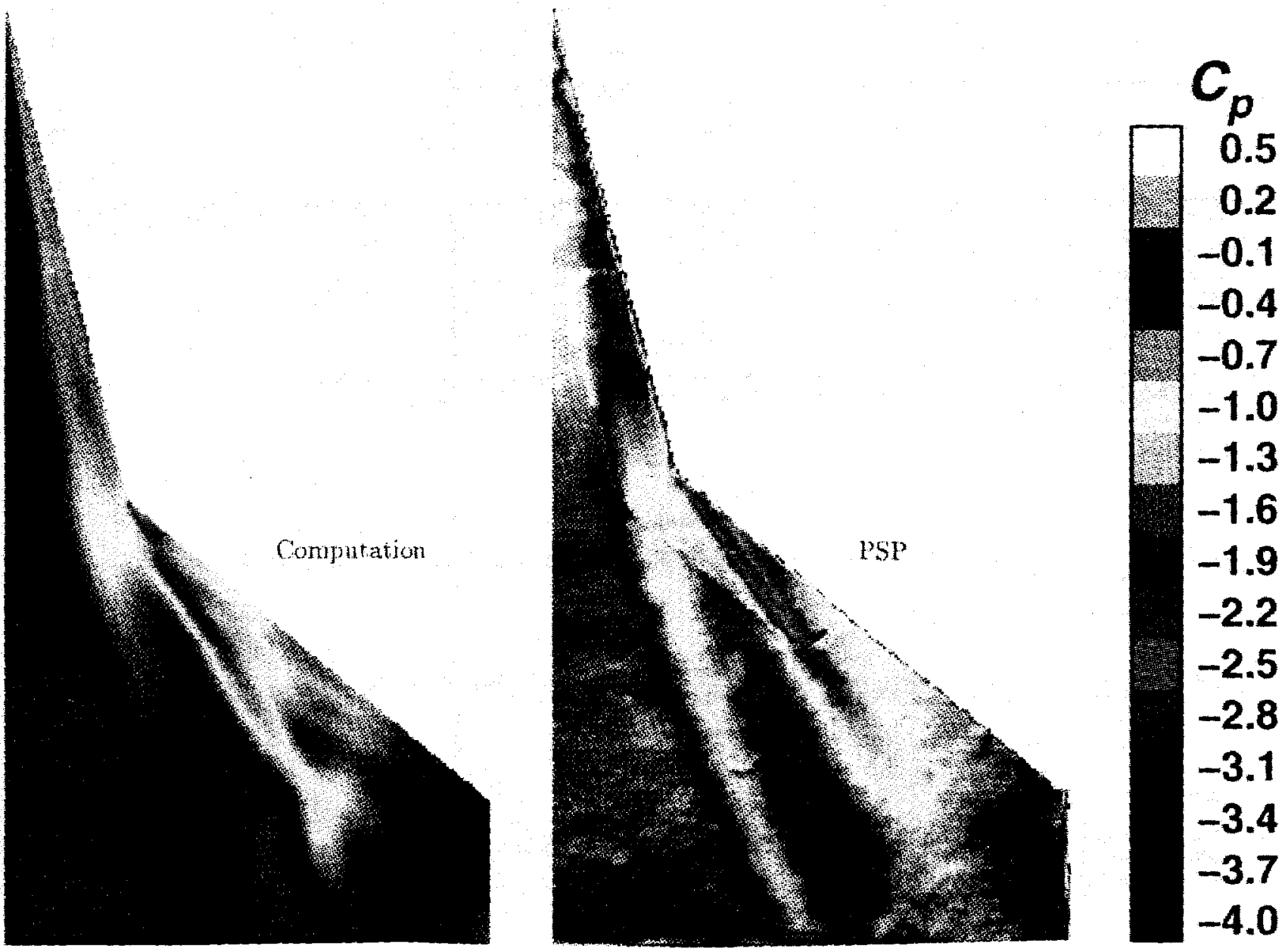

Figure 25: Upper surface $C p$ at $A O A=10 \mathrm{deg}$; computation and PSP results 


\begin{tabular}{|c|c|c|c|}
\hline \multicolumn{3}{|c|}{ REPORT DOCUMENTATION PAGE } & $\begin{array}{l}\text { Form Approved } \\
\text { OMB No. 0704-0188 }\end{array}$ \\
\hline \multicolumn{4}{|c|}{ 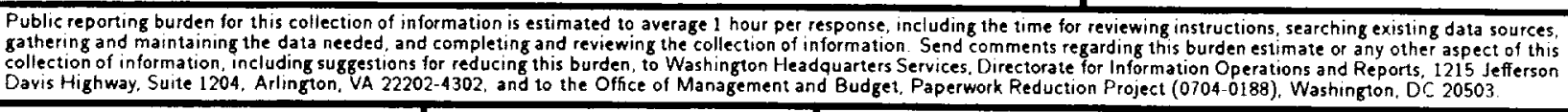 } \\
\hline 1. AGENCY USE ONLY(Leave blank) & $\begin{array}{l}\text { 2. REPORT DATE } \\
\text { February } 1995\end{array}$ & \multicolumn{2}{|c|}{$\begin{array}{l}\text { 3. REPORT TYPE AND DATES COVERED } \\
\text { Contractor Report }\end{array}$} \\
\hline \multicolumn{3}{|c|}{$\begin{array}{l}\text { 4. TITLE ANO SUBTITLE } \\
\text { A STUDY OF THE VORTEX FLOW OVER } 76 / 40 \text {-deg DOUBLE- } \\
\text { DELTA WING }\end{array}$} & \multirow[t]{2}{*}{$\begin{array}{l}\text { 5. FUNDING NUMBERS } \\
\text { C NAS1-19480 } \\
\text { WU } 505-90-52-01\end{array}$} \\
\hline \multicolumn{3}{|c|}{$\begin{array}{l}\text { 6. AUTHOR(S) } \\
\text { N. G. Verhaagen, L. N. Jenkins, S. B. Kern, A. E. Washburn }\end{array}$} & \\
\hline \multicolumn{2}{|c|}{$\begin{array}{l}\text { 7. PERFORMING ORGANIZATION NAME(S) AND ADDRESS(ES) } \\
\text { Institute for Computer Applications in Science } \\
\text { and Engineering } \\
\text { Mail Stop 132C, NASA Langley Research Center } \\
\text { Hampton, VA 23681-0001 }\end{array}$} & & $\begin{array}{l}\text { 8. PERFORMING ORGANIZATION } \\
\text { REPORT NUMBER } \\
\text { ICASE Report No. } 95-5\end{array}$ \\
\hline \multicolumn{3}{|c|}{$\begin{array}{l}\text { 9. SPONSORING/MONITORING AGENCY NAME(S) AND ADDRESS(ES) } \\
\text { National Aeronautics and Space Administration } \\
\text { Langley Research Center } \\
\text { Hampton, VA } 23681-0001\end{array}$} & $\begin{array}{l}\text { 10. SPONSORING/MONITORING } \\
\text { AGENCY REPORT NUMBER } \\
\text { NASA CR-195032 } \\
\text { ICASE Report No. } 95-5\end{array}$ \\
\hline \multicolumn{4}{|c|}{$\begin{array}{l}\text { 11. SUPPLEMENTARY NOTES } \\
\text { Langley Technical Monitor: Dennis M. Bushnell } \\
\text { Final Report } \\
\text { AIAA Paper } 95-0560\end{array}$} \\
\hline \multicolumn{2}{|c|}{$\begin{array}{l}\text { 12a. DISTRIBUTION/AVAILABILITY STATEMENT } \\
\text { Unclassified-Unlimited } \\
\text { Subject Category } 34\end{array}$} & & 12b. DISTRIBUTION CODE \\
\hline \multicolumn{4}{|c|}{$\begin{array}{l}\text { 13. ABSTRACT (Maximum } 200 \text { words) } \\
\text { A low-speed wind-tunnel study of the flow about a } 76 / 40 \text {-deg double-delta wing is described for angles of attack } \\
\text { ranging from }-10 \text { to } 25 \text { deg and Reynolds numbers ranging from } 0.5 \text { to } 1.5 \text { Million. The study was conducted to } \\
\text { provide data for the purpose of understanding the vortical flow behavior and for validating Computational Fluid } \\
\text { Dynamics methods. Flow visualization tests have provided insight into the effect of the angle of attack and Reynolds } \\
\text { number on the vortex-dominated flow both on and off of the surface of the double-delta wing. Upper surface pressure } \\
\text { recordings from pressure orifices and Pressure Sensitive Paint have provided data on the pressures induced by the } \\
\text { vortices. Flowfield surveys were carried out at an angle of attack of } 10 \text { deg by using a thin } 5 \text {-hole probe. Numerical } \\
\text { solutions of the compressible thin-layer Navier-Stokes equations were conducted and compared to the experimental } \\
\text { data. }\end{array}$} \\
\hline \multirow{2}{*}{\multicolumn{3}{|c|}{$\begin{array}{l}\text { 14. SUBJECT TERMS } \\
\text { Vortex Flow; Double-Delta Wing; Low-speed Wind Tunnel; Thin-Layer Navier-Stokes } \\
\text { Equations }\end{array}$}} & $\begin{array}{l}\text { 15. NUMBER OF PAGES } \\
33 \\
\end{array}$ \\
\hline & & & $\begin{array}{r}\text { 16. PRICE CODE } \\
\mathrm{A} 03\end{array}$ \\
\hline $\begin{array}{l}\text { 17. SECURITY CLASSIFICATION } \\
\text { OF REPORT } \\
\text { Unclassified }\end{array}$ & $\begin{array}{l}\text { 18. SECURITY CLASSIFICATION } \\
\text { OF THIS PAGE } \\
\text { Unclassified }\end{array}$ & $\begin{array}{l}\text { 19. SECURITY CLASSIFICATION } \\
\text { OF ABSTRACT }\end{array}$ & $\begin{array}{l}\text { 20. LIMITATION } \\
\text { OF ABSTRACT }\end{array}$ \\
\hline NSN 7540-01-280-5500 & & s & $\begin{array}{l}\text { Standard Form 298(Rev. 2-89) } \\
\text { Prescribed by ANSI Std. Z39-18 } \\
298-102\end{array}$ \\
\hline
\end{tabular}


National Aeronautics and Space Administration

BULK RATE Langley Research Center

Mail Code 180

Hampton, VA 23681-00001

POSTAGE \& FEES PAID

NASA

Official Business

Penalty for Private Use, $\mathbf{\$ 3 0 0}$ 
